\title{
Consumptor economicus: How do consumers form expectations on economic variables?*
}

\author{
Edda Claus ${ }^{a, b, \dagger}$, Viet Hoang Nguyen ${ }^{c}$ \\ ${ }^{a}$ Department of Economics, Wilfrid Laurier University, Canada \\ ${ }^{b}$ CAMA, Crawford School of Public Policy, Australian National University, Australia \\ ${ }^{c}$ Melbourne Institute of Applied Economic and Social Research, University of Melbourne, Australia
}

April 2018

\begin{abstract}
Consumptor economicus, the economic consumer, is more complex than homo economicus. We find consumers form monthly expectations on inflation, unemployment and economic conditions based on coherent evaluations of relevant news. Relevant information is incorporated gradually, leading to a transient bias in consumer expectations, an established result. But expectations are also based on emotional responses to irrelevant events. We borrow the partisan bias from the political science and social psychology literature to identify exogenously emotional responses. Our results demonstrate that consumers also incorporate irrelevant emotive events immediately, leading to a persistent emotional bias in expectations, a new result.
\end{abstract}

Keywords: Consumer Expectations, Consumer Behavior, Information Rigidities, Consumer Biases, Partisan Bias, News, Emotions.

JEL classification: E71; E37; D84.

\footnotetext{
*We thank Michael Ehrmann, Bradley Ruffle, Nalini Prasad, Efrem Castelnuovo and participants at the 50th Annual Conference of the CEA, 3 - 5 June 2016 at the University of Ottawa, and participants at the Rimini Conference in Economics and Finance (RCEF2016), 16 - 18 September 2016, Waterloo Canada for valuable comments and suggestions. We are particularly grateful to two anonymous referees. Their comments and suggestions have greatly improved the paper.

${ }^{\dagger}$ Corresponding author: Department of Economics, Wilfrid Laurier University, 75 University Avenue West, Waterloo ON, N2L 3C5, Canada.

E-mail addresses: eclaus@eddaclaus.com (Edda Claus), vietn@unimelb.edu.au (Viet Hoang Nguyen)
} 


\section{Motivation}

Expectations play a key role in macroeconomics but how do ordinary consumers actually form views on macroeconomic variables? We find consumers form expectations on inflation, unemployment and economic conditions based on a combination of reasoning, emotions and perceptions. Consumers incorporate structural economic information gradually, leading to a transient bias in expectations, an established result. Revealing their partisan bias, consumers also incorporate irrelevant emotive events immediately leading to a persistent emotional bias in expectations, a new result.

We regress consumer expectations from the monthly Consumer Attitudes, Sentiments and Expectations (CASiE) survey, the Australian version of the Michigan Survey of Consumers, on relevant economic news and on irrelevant emotive events. If relevant information affects expectations, reasoning plays a role in expectations formation; if irrelevant yet deterministic events have a persistent impact on actual consumer forecasts, this suggests that emotions also affect consumer expectations. The term 'irrelevant' here is used for events that are clearly extrinsic to the underlying data generating process (DGP) of the variable to be forecast. We rely on economic theory to identify relevant information and borrow from the political science and social psychology literature to identify exogenously irrelevant emotive events. The political science literature proposes that voting choice impacts views on the economy; see Erikson (2004), Wlezien et al. (1997), Evans and Andersen (2006) and Gerber and Huber (2009) for empirical applications. The presence of this 'partisan screen' means that voters take a favourable view on the economy if they support the incumbent government and take a less favourable view on the economy if they dislike the incumbent irrespective of actual real economic activity! From a social psychology standpoint, partisanship is driven by a person's attitude that consists of cognitive, affective, and behavioral components and by the person's group attachment; see Greene (2002). Leigh (2005) finds that a large portion of voter behavior in Australia is driven by the affective component of partisanship (feelings, moods and emotions) which allows us to use partisanship to identify exogenously emotional responses. ${ }^{2}$

We apply simple ordinary least squares (OLS) and regress consumer expectations on variables that broadly cover the macroeconomy, i.e., measures of unemployment, inflation, activity, monetary policy and financial markets and match federal election dates that brought a change in government in Australia with CASiE survey dates. Results suggest that consumers form expectations by evaluating economic data but also by emotionally

\footnotetext{
${ }^{1}$ Although confirmation bias and partisan bias are related, the former is about ex post evaluations of events and the latter on ex ante evaluations.

${ }^{2}$ We thank one of the anonymous referees for the clarification why elections with a change of government can be identified as an emotive event.
} 
reacting to the party in power. We show that a change in government lowers expected inflation and expected unemployment, and raises the economic outlook of respondents who support the incoming government; for respondents who support the outgoing government, the change raises expected inflation and expected unemployment, and lowers the economic outlook. The effect persists until the government changes again, ceteris paribus. Bovi (2009) demonstrates a persistent bias that is consistent with overoptimistic consumers but can only speculate on that link while Barsky and Sims (2012) posit that emotions only have small and transient effects.

Perceptions also seem important for inflation expectations. We define perceptions as "[t]he way in which something is regarded, understood, or interpreted." 3 There are two aspects to consumers' inflation forecasting. On the one hand, the effects of relevant economic information indicate that inflation expectations formation is theory-consistent with a Phillips curve. On the other hand, the effects of emotive events indicate that consumers seem to regard high inflation as 'bad' and low inflation as 'good' which leads to inflation expectations that are not theory consistent with unemployment expectations.

Perhaps surprisingly, inflation expectations rise in response to a rise in the target cash rate (Australia's monetary policy rate) and expectations fall in response to a decline in the target cash rate. If the central bank has private information or is simply a better forecaster than consumers, a change in policy can convey new information on the state of the economy. When consumers update their forecasts in response to these signals, consumer responses may seem atheoretical; see García-Schmidt (2015). Here, a rise in the target cash rate seems to be interpreted as a signal that the central bank expects robust growth, inflationary pressures, and lower unemployment. A decline in the target cash rate is regarded as a signal of moderating growth and inflation, and upward pressure on unemployment.

The importance of emotions and perceptions in consumer expectations formations likely contributes to consumers forming expectations that are not consistent with economic theory. Recent evidence from the Michigan Survey of Consumers shows that expectations of the majority of U.S. consumers are not consistent with economic theory; Carvalho and Nechio (2014) demonstrate that at least some households form expectations that are consistent with a Taylor (1993)-type rule while Dräger et al. (2016) find that only 6\% of consumers form expectations consistent with all three concepts: the Phillips curve, the Taylor rule and the Income Fisher equation. Malmendier and Nagel (2016) show that, when forming macroeconomic expectations, individuals put a higher weight on realizations of macroeconomic data experienced during their life-times compared with other available

\footnotetext{
${ }^{3}$ Oxford Dictionaries https://en.oxforddictionaries.com/definition/perception; Accessed 23 January 2018.
} 
historical data. Claus and Nguyen (2015) find that, on average, younger consumers (1834 years old) are more likely to form inflation and unemployment expectations consistent with a Phillips curve than older groups (35 years old and above), perhaps reflecting the periods of high inflation and unemployment over the 1970s and 1980 followed by low and stable inflation since the introduction of inflation targeting in Australia in 1992.

The limited empirical literature on consumer expectations suggests that consumer forecasts are biased; see, for example, Mankiw et al. (2004), Bovi (2009), Coibion and Gorodnichenko (2015a b) and Lamla and Lein (2014). This bias could be the results of rigidities where consumers incorporate new information only slowly into their forecasts. Several explanations have been put forward in the economics literature to account for these rigidities. Mankiw and Reis (2002) propose a sticky information model where information is costly to acquire and to evaluate, leading agents to update their expectations only periodically. This means that new information is only gradually incorporated in expectations. Woodford (2003) models rigidities within a signal to noise extraction problem. Agents understand the underlying DGP and continuously update their information set but have to filter information on the true state of the economy from noise. Sims (2003) contends that agents display 'rational inattention' because they have only limited capacity to process information while Carroll (2003) suggests that consumers only occasionally pay attention to news reports whose interpretations of underlying information are used to update expectations. These explanations are firmly rooted in economics, in the sense that the rigidities are caused by costs and incentives, and lead to a transient bias in consumer expectations but asymptotically rational forecasts. Our results align with the information rigidities literature. We find consumers fully incorporate economic news into expectations about six months following the data release. Our contribution is that consumer expectations formation is more complex. Our goal is not to demonstrate the existence of the partisan bias. Rather, we borrow from the existing political science and social psychology literature to identify exogenously emotive events. This exogenous identification allows us to examine the effects of emotions on consumer expectations. Information rigidities introduce a transient bias in expectations while emotions introduce a persistent bias.

The CASiE dataset offers a unique opportunity to explore how consumers form expectations. CASiE is a monthly survey since February 1990 that maps directly into the Michigan Survey of Consumers. CASiE includes consumer expectations on the three major macroeconomic variables: inflation, unemployment and economic conditions and, most importantly, it has been canvassing respondents' voting intentions at every month since 1990. The Michigan Survey of Consumers does not contain regular information on the political persuasion of respondents but, using special surveys between January and July 1984, Lewis-Beck (1988) establishes the presence of the partisan bias in the dataset. Finally, CASiE includes a full growth cycle, demonstrating that results presented here do 
not depend on a particular phase of the business cycle.

The remainder of this paper is organized as follows. Section 2 gives a detailed description of CASiE, its match to Australian federal election dates and shows that CASiE maps into the Michigan Consumer Survey. The section also discusses the structural economic news. Section 3 outlines the empirical framework and Section 4 presents the results. Section 5 is a robustness check and the final Section 6 discusses the implications of the empirical results for economists.

\section{Data}

Our dataset comprises CASiE consumer expectations and voting intentions, election dates and economic data. The Westpac-Melbourne Institute CASiE survey started in March 1973 and has been a monthly telephone survey since February 1990 with a sample size of 1200 households since March 1993. Prior to March 1993, the sample size varied between 1000 to 2500 households. The sample is stratified by age, gender and state. This stratification, together with the random sampling of respondents, leads to a representative survey of the Australian population. Responses are cross-classified by age, gender, state, capital city, education, occupation, household income, work status, voting intention and home ownership. Unlike the Michigan Survey of Consumers, no households are re-interviewed so that the survey is a pure repeated cross-section.

\subsection{Expectations data}

Among other questions, respondents are asked about their expectations on economic conditions (consumer economic conditions expectation, CEE), unemployment (consumer unemployment expectation, CUE) and inflation (consumer inflation expectation, CIE) during the next 12 months. The answers to the survey questions are ordinal, such as 'better-off'/'good', 'same', 'worse-off'/'bad' or 'don't know'. The CUE and CIE questions were added in 1974 and have been monthly since June 1993. For this paper, monthly observations of CUE and CIE within a quarter prior to June 1993 are assumed the same as the quarterly value..$^{4}$

We focus on these key questions about general conditions (as opposed to household-specific conditions) with the same forecast horizon to examine consumer expectations formation processes. The actual wordings of these questions are as follows:

\footnotetext{
${ }^{4}$ For inflation expectations, prior to June 1993, the data were quarterly with a monthly trial period between November 1991 and December 1992.
} 
CEE. "Thinking of economic conditions in Australia as a whole. During the next 12 months, do you expect we'll have good times financially, or bad times, or what?"

1. Good times

2. Good with qualifications

3. Some good, some bad

4. Bad with qualifications

5. Bad times

6. Uncertain/Don't Know/It depends

CUE. "Now about people being out of work during the coming 12 months. Do you think there'll be more unemployment than now, about the same, or less?"

1. More unemployment

2. About the same/Some more some less

3. Less unemployment

4. Don't know

CIE. "I would like to find out what you think will happen to prices. Thinking about the prices of things you buy, by this time next year, do you think they will have gone up or down?"

1. Up

2. Down

3. The same

4. Don't know

From consumers' answers to these questions, we compute two weighted proportions: (i) 'Up' proportion (for those who select options (1) and (2) in CEE, and option (1) in CUE and CIE), (ii) the 'Same/Down' proportion (for those who select options (3), (4) and (5) in CEE, and option (2) and (3) in CUE and CIE). Weights are based on stratification factors from census surveys of the Australian Bureau of Statistics (ABS), and are normalized to sum to 100 percent. We group 'Same' and 'Down' answers together to simplify our framework without affecting the results. The 'Same' and 'Down' proportions are usually smaller than the 'Up' proportion, thus grouping 'Same' and 'Down' proportions together amounts to a proportion similar in size to the 'Up' proportion. This helps facilitate a reliable comparison against the 'Up' proportion. The results for a separate 'Down' proportion are qualitatively similar and are available on request. One might argue that if 'Same' and 'Down' proportions are grouped together for expectations on economic activity (CEE) 
and inflation (CIE), then 'Same' should be grouped with 'Up' for unemployment expectations (CUE). For practical reasons we also group 'Same' with 'Down' for unemployment expectations. The proportion of respondents expecting a rise in unemployment over the next 12 months rarely goes below 60 percent. Grouping the 'Same' proportion with the 'Up' proportion will bring the number close to 100 percent over the global financial crisis. Grouping 'Same' with 'Down' leads to similar empirical results to just 'Down' proportions while the grouping includes a comparable number of respondents as the 'Up' proportion.

We use Up proportions to proxy for consumers expecting improved economic conditions (in CEE), rising unemployment (in CUE) and inflationary pressure (in CIE), and Same/Down proportion to proxy for expected stable or worsening economic conditions (in CEE), stable or declining unemployment (in CUE) and subdued inflation (in CIE). We include both Up and Same/Down proportions in our analysis because an increase (decrease) in the Up proportion does not always translate into an equal decrease (increase) in the Same/Down proportion due to the presence of the 'Don't know' respondents. Moreover, the inclusion of these two proportions can be used to check if consumers are consistent and symmetric in their upward and downward expectations.

The CIE question is about prices rather than inflation, an expected rising price level may not be indicative of expected rising inflation pressures if the expected increase in prices is below the current inflation rate (though an expected declining price level is mostly indicative of expected declining inflation pressures). We therefore also use the CIE follow-up question

CIE follow-up. (for interviewees who select Up and Down in CIE question) "By what percentage do you think prices will have gone up/down by this time next year?"

- Record numerical response.

to compute CIE's alternative Up and Same/Down proportions based on numerical responses. Those selecting 'Same' in the initial CIE question are coded as expecting $0 \%$ inflation. The Up proportion consists of respondents expecting a change in prices greater than the latest released inflation rate and Same/Down proportion consists of respondents expecting a change in prices equal to or lower than the latest released inflation rate.

\section{$2.2 \quad$ Voting intentions}

The Australian political system is a multi-party system but the political landscape is dominated by the Australian Labor Party $5^{5}$ (ALP) and the Liberal-National Party (LNP)

\footnotetext{
${ }^{5}$ Although Australia uses British spelling, Labor is spelled without the ' $u$ '.
} 
coalition, a long-standing coalition (since 1944) between the Liberal Party of Australia and the National Party of Australia. The ALP has a democratic socialist ideology and is officially associated with labor unions. It combines both environmental and socially liberal issues. The Liberal Party of Australia has a conservative liberal ideology. It takes a relatively hands-off approach to economic affairs and supports free trade, family values and small government. The National Party of Australia (formerly the Country Party of Australia) has much policy overlap with the Liberal Party with the biggest distinction that its focus is on rural people; see Singh (2009). Party focus for both has remained fairly constant with the biggest shifts in refugee policy where both have moved towards a stricter approach, the LNP in the early 2000's and the ALP in the late 2000's.

The Australian Parliament consists of the House of Representatives (the executive branch of government) and the Senate (the legislative branch of government). Voting in Australia is compulsory and votes are allocated to candidates using a preferential voting system. The electoral system between the House of Representatives and the Senate differs resulting in minor political parties, with very few exceptions, only elected to the Senate (Singh, 2009). All governments since Federation in 1901 (Australian independence from the United Kingdom), were formed either by the ALP or the LNP and its direct predecessors ${ }^{6}$ This means that excluding voting intentions for minor parties should not affect our empirical results. The combination of compulsory and preferential voting may re-enforce party loyalty; see Jackman (2003).

To disaggregate consumers by their voting intentions, we use the following survey question:

VOTE. "If a federal election was held today could you please tell me which party you personally would vote for?"
1. Liberal Party
2. Australian Labor Party
3. Australian Democrats
4. The National Party
5. Greens
6. Independents/other
7. None/DK

From the responses to this question, we only group consumers into major groups: (i) Coalition voters - options (1) and (4); and (ii) Labor voters - option (2). Voters for these two account for around $70 \%$ of eligible voters in Australia. Respondents are asked about

\footnotetext{
${ }^{6}$ the first Liberal Party, the Nationalist Party, the United Australia Party, and from 1944 the Liberal Party; see Jackman (2003)
} 
their voting intentions before the questions on the economy, unemployment and inflation. This may prime partisanship in the responses and may re-enforce the correlation between voting intentions and expectations; see Gerber and Huber (2009) and Erikson (2004) op cit. We acknowledge that this may bias our results.

Our empirical analysis starts from February 1990 and ends in May 2016. Figure1 provides a graphical representation of the expectations data and Table 1 presents the descriptive statistics. Shaded areas in the figure indicate years the Australian Labor Party formed government. In the remaining unshaded years, Australia had a Coalition government. Figures 1(a) and1(b) give the proportions of Labor and Coalition voters. Each proportion is typically around 30\% with greater variation for Labor voters towards the end of the sample period. The relatively large decline in Labor voting intentions in the early 2010s, that was not matched by an equally large rise in Coalition voting intentions, likely reflects a rise in support for the Australian Greens.7 Overall, voting intentions for Coalition and Labor are similar, with means of $36.4 \%$ for the Coalition and $32.1 \%$ for Labor and standard deviations of $5.1 \%$ and $5.3 \%$.

\section{— Insert Figure 1 and Table 1 around here -}

The remaining charts in Figure 1 give the four sets of expectations disaggregated by voting intentions. Figure 1(c) gives the proportion of respondents expecting unemployment to rise over the next 12 months (Up proportion) and Figure 1(d) gives the proportion of respondents expecting unemployment to stay the same or decline over the next 12 months (Same/Down proportion). Similarly, Figures 1(e) and 1(f) plot these two proportions for economic conditions. There are two sets of inflation expectations. Figures 11(g) and 1(h) plot the proportions based on ordinal responses and Figures 1(i) and 1(j) plot the proportions based on numerical responses. Each figure gives the proportion of Labor voters in black solid lines and the proportion of Coalition voters in gray dashed lines.

When Labor is in power (shaded years), the proportion of Coalition voters expecting unemployment and inflation to rise over the next 12 months is persistently higher than the corresponding proportion of Labor voters, and the share of Labor voters expecting economic conditions to be good is persistently higher than the corresponding share of Coalition voters. The reverse is true when the Coalition is in government (years without shade). Similarly, the proportion of Labor voters expecting unemployment and inflation to stay the same or fall over the next 12 months is persistently higher than the corresponding proportion of Coalition voters when Labor is in power, and is persistently lower than the proportion of Coalition voters when the Coalition is in government. The proportion of

\footnotetext{
${ }^{7}$ http://greens.org.au/our-story
} 
Labor voters expecting economic conditions to be the same or bad over the next 12 months is lower than that of Coalition voters when Labor is in power and is higher than that of Coalition voters when the Coalition is in power.

Figure 1 foreshadows the empirical results of the paper. Voting intentions clearly impact consumer expectations formations. There is a clear gap between the expectations of the two sets of voters. Labor voters have a more optimistic outlook than Coalition voters when Labor is in power and Coalition voters have a more optimistic outlook than Labor voters when the Coalition is in power. Importantly, optimism and pessimism switches at election dates when ruling parties changed.

\subsection{Elections dates}

Reflecting mandatory voting, voter turn-out for Australian federal elections has been in excess of $90 \%$ since $19258^{8}$ There are 9 Australian federal elections in our sample period with Labor winning 4 and the Coalition winning 5. There was a change in government on three occasions. First, in the 2 March 1996 election, the Labor government led by Prime Minister Paul Keating was ousted by the Coalition led by John Howard. Second, in the 24 November 2007 election, Prime Minister John Howard's Coalition government was defeated by the Labor Party led by Kevin Rudd. The last change in government in our sample occurred in the 7 September 2013 election when the Labor government led by Prime Minister Kevin Rudd was ousted by the Coalition led by Tony Abbott.9

\begin{aligned} & \hline ELECTION DATE WinNiNG PARTY \\ & \hline 24-Mar-1990 Labor \\ & 13-Mar-1993 Labor \\ & 2-Mar-1996 Coalition \\ & 3-Oct-1998 Coalition \\ & 10-Nov-2001 Coalition \\ & 9-Oct-2004 Coalition \\ & 24-Nov-2007 Labor \\ & 21-Aug-2010 Labor \\ & 7-Sep-2013 Coalition \\ & \hline\end{aligned}

We map these three elections with the change in government into the CASiE survey to investigate how a change in the governing party affects the expectations formation process

\footnotetext{
8 http://www.aec.gov.au/Elections/Australian_Electoral_History/Voter_Turnout.htm

${ }^{9}$ During Labor's time in government, Prime Minister Rudd was replaced by Julia Gillard on 24 June 2010. Labor under Julia Gillard won the August 2010 federal election as a minority government. Prime Minister Gillard was replaced by Kevin Rudd on 27 June 2013 just before the September 2013 federal election that brought in Tony Abbott. Prime Minister Abbott was replaced by Malcolm Turnbull on 15 September 2015. The Coalition government was returned on 2 July 2016 but that election date is after the end of our sample period.
} 
of Australian consumers. Specifically, the 2 March 1996 election was before the March 1996 survey so it is mapped into the March 1996 survey. The 24 November 2007 election occurred after the November 2007 survey, so it is mapped into the December 2007 survey. The 7 September 2013 election occurred during the September 2013 survey (from 2 to 8 September 2007) with 886 respondents being surveyed before the election day and the rest being surveyed on and after it. Figure 1 suggests that the effect of the 7 September 2013 election was immediately present in expectations of Labor and Coalition voters, and hence this election is mapped into the September 2013 survey.

\subsection{Economic data}

We use publicly released news about the unemployment rate, the target cash rate, the stock market (the ASX/S\&P200 index), the consumer price index (CPI), and real gross domestic product (GDP) to proxy for structural news. These variables embody representative structural information about the labour market, financial markets, real economic activity, monetary policy and inflation. We only include data that were available during the actual survey. In Australia, CPI inflation and GDP are only available at quarterly frequencies. Adding the publication lag of both releases means that information on CPI inflation is always one quarter old and the information on real GDP growth is always two quarters old. Therefore, for inflation 'latest news' and '3-month old news' are the same (i.e., 1 quarter old) while for real GDP, 'latest news', '3-month old news' and '6-month old news' are the same (i.e., 2 quarters old). Public news about these major economic variables between CASiE survey periods $t$ and $t-1$ are defined as changes that occurred after survey period $t-1$ but before survey period $t$. In essence, these news series are innovations to the underlying economic variables whose DGPs are assumed to follow a random walk. Alternatively, news series can be defined as innovations to autoregressive DGPs of the underlying economic variables. Our empirical findings are robust to either DGPs. For simplicity and without loss of generality, the empirical results presented below are based on the random walk DGPs.

Specifically, $u r_{t}$ denotes the first differences of the monthly unemployment rate (measured in percentage points, ppt.), $r_{t}$ denotes the first differences of the monthly target cash rate (in ppt.), $s_{t}$ denotes the monthly change in the ASX/S\&P 200 (in \%), $\pi_{t}$ denotes the monthly CPI inflation rate (in \%) and $g_{t}$ denotes the monthly growth in real GDP (in \%). Since Australia's CPI inflation rate and real GDP growth rate are quarterly information, their monthly observations within a quarter are assumed to be equal to their quarterly value for simplicity. The results based on linearly interpolated monthly series are quantitatively similar and are available on request. Figure 2 plots these news series and Table 2 provides their descriptive statistics and data sources. The ADF test results 
in Table 2 confirm that these news series are stationary.

— Insert Figure 2 and Tables 2 around here

\subsection{Mapping CASiE to the Michigan Survey of Consumers}

The empirical results presented in this paper seem to reflect general consumer behavior rather than results specific to Australia. Australian data closely align with the Michigan Survey of Consumers. This is not surprising, given the Michigan Survey was used as a template for CASiE and there is no obvious reason why U.S. consumers are fundamentally different from their Australian counterparts. Replicating the three-variable vector autoregression (VAR) in Barsky and Sims (2012) on the Australian CASiE and macro data leads to analogous empirical results. Barsky and Sims (2012) apply a VAR in levels to detrended real GDP and consumption of goods and services, and expected economic conditions over the next 5 years (E5Y). The variable E5Y summarizes responses to the survey question: "Turning to economic conditions in the country as a whole, do you expect that over the next five years we will have mostly good times, or periods of widespread unemployment and depression or what?" Barsky and Sims (2012) [p. 1347].

Insert Figure 3 around here ——

We apply an analogous VAR in levels with a constant and two lags (suggested by AIC) between 1975Q1 and 2016Q1 to Australian detrended real GDP (Y) and household final consumption expenditure $(\mathrm{C})$, and CASiE's Index relating to expected economic conditions over the next 5 years (E5Y) ("Looking ahead, what would you say is more likely? That in Australia as a whole, we'll have continuous good times during the next 5 years or so, or we'll have some bad times - or what?" We do not use this survey question in our main empirical applications.) The empirical results for Australia are both qualitatively and quantitatively similar to those for the U.S. reported in Barsky and Sims (2012). Figure 3 provides the impulse responses (IRFs) of Y, C and E5Y to E5Y innovations with E5Y being ordered first (left column) and ordered last (right column). These IRFs align closely to those in Figure 2 and Figure 3 in Barsky and Sims (2012) [p. 1349-1350]. Specifically, a one-standard-deviation innovation to E5Y raises the level of Australian output and consumption about 0.8 and 0.6 per cent, after 40 quarters as compared to the corresponding 0.6 per cent (for both output and consumption) for the U.S. in Barsky and Sims (2012) 10

\footnotetext{
${ }^{10}$ Investigating consumer reactions to monetary policy shocks, empirical applications to CASiE in Claus and Nguyen (2015) align with Carroll (2003) and Mankiw et al. (2004).
} 


\section{Empirical framework}

According to standard economic theory, consumers form expectations based on current relevant information. Adding rationality, this can be approximated as

$$
E_{t}\left(y_{t+m} \mid \Omega_{t}\right)=f\left(\mathbf{x}_{t}, \epsilon_{t}\right)
$$

where consumers' expected change in variable $y_{t}$ in $m$ months' time based on their current information set $\Omega_{t}$ is a function of $\mathbf{x}_{t}$ which is a vector of current relevant economic news about the current state of the economy, publicly available to all consumers; $\epsilon_{t}$ denotes disturbances around these economic news. $\Omega_{t}$ includes relevant economic information, publicly and/or privately available to consumers.

If consumers' expectation formation processes exhibit information rigidities and are also influenced by irrelevant information, then the consumers' expectation formation process can be rewritten as

$$
E_{t}\left(y_{t+m} \mid \Omega_{t}, b_{t}\right)=f\left(\mathbf{x}_{t-p}, b_{t}, \epsilon_{t}\right), \quad p=0, \ldots, m,
$$

where $\mathbf{x}_{t}$ is lagged $p$ periods and $b_{t}$ denotes irrelevant information, irrelevant in the sense that economic theory does not consider $b_{t}$ part of the DGP of $y_{t}$. The presence of $b_{t}$ allows for a bias extrinsic of structural information. For example, $b_{t}$ could be a 'feel good' effect demonstrated for sporting events (see, for example, Maenning and du Plessis (2007); Jasmand and Maenning (2008); Edmans et al. (2007)) or weather patterns (see, for example, Hirshleifer and Shumway (2003); Cao and Wei (2005); Kamstra et al. (2003)). As $b_{t}$ is not part of the true DGP of $y_{t}, b_{t}$ is orthogonal to $\mathbf{x}_{t}$. Practically, this means that misspecification of $\mathbf{x}_{t}$ does not impact on the estimated effects of $b_{t}$ in $E_{t}\left(y_{t+m} \mid \Omega_{t}, b_{t}\right)$. As a robustness check on the specifications of $\mathbf{x}_{t}$ (discussed below), we apply principal component analysis to a large dataset and express $\mathbf{x}_{t}$ as the first and second principal components whose eigenvalues sum to 4.511 The empirical results are robust to this change in specification.

Equation (2) is a very general specification that nests a range of theoretical models. For example, in forecasting inflation, the expected inflation expressed in (2) is consistent with an expectation-augmented Phillips curve (see Blanchard (1997), Clarida et al. (1999)), if $\mathbf{x}_{t-p}$ only contains information about the current inflation rate and the output gap (i.e. $p=0)$. Alternatively, expected inflation in (2) is consistent with a backward-looking Phillips curve where there is inertia or a lagged dependence structure in inflation ex-

\footnotetext{
${ }^{11}$ The first four principal components explain $50 \%$ of the variation in the large dataset, but adding the third and the fourth principal components does not change the results. Results are available on request.
} 
pectations (see Mankiw and Reis (2002)), if $\mathbf{x}_{t-p}$ also contains lagged information (i.e., $p=0, \ldots, m)$. We follow Gali and Gertler (1999) and use the most general specification which allows for both forward-looking and backward-looking behaviors of consumers simultaneously, i.e., $\mathbf{x}_{t-p}$ includes both current and lagged information.

We borrow from the political science literature to identify exogenously ex ante a subset of $b_{t}$ to investigate its influence on $E_{t}\left(y_{t+m}\right)$. The impact of economic activity on election outcomes seems straightforward. Citizens who are dissatisfied with the performance (or the perceived performance) of the economy are less likely to vote for the incumbent; see, for example, Lewis-Beck (1988). But causality may also go the opposite direction where political orientation may impact responses to questions on the economy. The political science literature posits that people who support the party in power have a more positive outlook on the economy and people who support the opposition have a more negative view on the economy. This partisan screen may reflect partisan loyalty, cognitive consistency or just the desire to provide consistent answers within a survey; see Evans and Andersen (2006). Opposition party wins are deemed irrelevant because no actual change in government has taken place and no new policies are actually implemented. Anticipated policy changes from the new government cannot fully explain the change in expectations because the bias remains persistent in size at lags until the opposition wins again. Gerber and Huber (2009) find that partisanship-induced changes in consumption occur at the election of a new U.S. state government rather than the actual change in government and hence policy, and Suzuki (1992) even finds evidence that the bias increases towards the end of the electoral cycle when new elections are approaching.

From a social psychology standpoint, partisanship is an attitude - a generalized and enduring positive or negative response to an object, but partisanship also fits in the concept of group identification; see Greene (2002). Attitudes consist of cognitive, affective, and behavioral components where evaluations of economic management are part of the cognitive component while the affective component consists of feelings, moods and emotions towards the attitude object. Group attachment is the degree of psychological attachment to a particular group measured by how close a respondent feels to a given group. Burden and Klofstad (2005) argue that partisanship is better measured when respondents are asked how they feel about their party rather than what they think about their party. Leigh (2005) calls the affective component of partisanship "innate ideological attachment" that is unrelated to a voter's individual characteristics, locality, or the state of the national economy and finds that the non-affective component only explains about 4 per cent of voting behavior in Australia between 1966 and 2001. So, although partisanship is not solely driven by emotions, partisanship allows us to identify exogenously emotional responses. 
A number of empirical studies have examined the causal link from partisanship to economic expectations. Based on a three wave panel in April and November 1982 and in April 1983 in Lexington, Kentucky, Conover et al. (1987) find that consumer forecasts for unemployment and inflation are driven by household characteristics and partisan assessments of governmental performance. Applying OLS, two stage least squares and probit models to the American National Election Studies (ANES) dataset ${ }^{12}$ between 1980 and 2000, Erikson (2004) finds that, in presidential election surveys, economic evaluations are almost entirely noise plus a bias based on the respondents' presidential choice. Lewis-Beck (1988) finds correlation between short and medium expectations about the economy and voting intentions using special Michigan Consumer Surveys between January and July 1984. Wlezien et al. (1997) apply OLS and full-information maximum likelihood to Eurobarometer ${ }^{13}$ data for Britain, France, Germany and Italy for Spring 1984 and find that vote choice matters for expectations on unemployment, inflation and aggregate activity. More recently, results from applying OLS and logit to data from the British Election Study (BES) ${ }^{14}$ between 1992 and 1997 in Gerber and Huber (2009) support the notion that partisanship affect economic expectations. Incorporating these ideas, we chose a very simple model to implement equation (2).

\subsection{Empirical model}

In our empirical investigation, we assume a linear relationship between consumer expectations and their determinants and approximate the consumer expectation formation process in equation (2) by a linear model. Specifically, we map Australian consumers' upward expectations (Up proportion) on unemployment, economic conditions and inflation during the next 12 months to major economic news and a partisan bias as:

$$
y_{i, t+12}^{u}=\alpha_{i}^{u}+\theta_{i}^{u} b_{i, t}+\boldsymbol{\beta}_{i}^{u \prime} \mathbf{x}_{t}+\epsilon_{i, t}^{u}, t=1, \ldots, T
$$

where $y_{i, t+12}^{u}$ denotes the proportion of voters for party $i$ expecting that $y_{t}$ will go up during the next 12 months with $i=\{$ Coalition, Labor $\}$, and $y_{t}=\{$ unemployment, economic

\footnotetext{
12 "Time Series Studies are conducted during years of national elections. In presidential election years, the study is typically conducted both before and after the election (that is, a pre-election survey and a post-election survey), while for congressional election years the study has typically been conducted only after the election (a post-election survey)." http://www.electionstudies.org/overview/overview. htm accessed 21 June 2016

${ }^{13}$ Eurobarometer is a public bi-annual opinion survey conducted on behalf of the European Commission since September 1973. "It looks at the main concerns of Europeans at national and at European level and considers how respondents perceive the current economic situation, what they expect for the next twelve months and their opinions of the euro." http://ec.europa.eu/public_opinion; accessed 21 June 2016

${ }^{14}$ The BES, created in 1964, is a panel of about 3,500 households conducted every general elections. Questions cover political and socio-economic views and household characteristics; see http: //www.britishelectionstudy.com/; accessed 21 June 2016
} 
conditions, price level/inflation rate $\} ; \alpha_{i}^{u}$ is a constant; $b_{i, t}$ is a dummy variable taking the value of 1 for all the months during the sample period that party $i$ is in power and 0 otherwise; $\mathbf{x}_{t}^{u}=\left(u_{t}, r_{t}, s_{t}, \pi_{t}, g_{t}\right)^{\prime}$ denotes the set of the latest news about the unemployment rate, the target cash rate, the ASX/S\&P200 index, CPI inflation and real GDP growth, as defined in Subsection 2.4; $\theta_{i}^{u}$ and $\boldsymbol{\beta}_{i}^{u}=\left(\beta_{i, u r}^{u}, \beta_{i, r}^{u}, \beta_{i, s}^{u}, \beta_{i, \pi}^{u}, \beta_{i, g}^{u}\right)^{\prime}$ are parameters to be estimated; $\epsilon_{i, t}^{u}$ is the error term. $\beta_{i, j}^{u}$, with $j=u r, r, s, \pi, g$, can be interpreted as follows: an increase of 1 percentage point (or \%) in variable $j$ raises (if $\beta_{i, j}^{u}>0$ ) or reduces (if $\beta_{i, j}^{u}<0$ ) the proportion of party- $i$ voters expecting $y_{t}$ to go up during the next 12 months by $\beta_{i, j}^{u}$ percentage points. The estimated value of $\theta_{i}^{u}$ is interpreted similarly. If an emotional partisan bias exists in the expectations formation process of consumers, then $\theta_{i}^{u}$ will be statistically significant.

Similarly, for the Same/Down proportion, we estimate the following equation for each group of voters:

$$
y_{i, t+12}^{s d}=\alpha_{i}^{s d}+\theta_{i}^{s d} b_{i, t}+\boldsymbol{\beta}_{i}^{s d \prime} \mathbf{x}_{t}+\epsilon_{i, t}^{s d}, t=1, \ldots, T
$$

where $y_{i, t+12}^{s d}$ denotes the proportion of voters for party $i$ expecting that $y_{t}$ will remain the same or go down during the next 12 months. The remaining variables and parameters are defined analogously to those in equation (3).

So, for each set of expectations, we estimate four regressions, one for the proportion of respondents expecting a rise in the underlying macroeconomic variable and one regression for those expecting no change or a decrease in the macroeconomic variable, leading to four regressions in total as respondents are disaggregated by voting intentions. The voting intentions dummy $b_{i}$ for Labor voters takes the value of 1 for all months Australia had a Labor government between February 1990 and May 2016 and 0 otherwise while the voting intentions dummy $b_{i}$ for Coalition voters takes the value of 1 for all months Australia had a Coalition government and is 0 otherwise. A statistically significant estimate of $\theta_{i}$ indicates that the shift in the governing party affects economic expectations of voters for party $i$, independent of current economic conditions. For example, if $\theta_{L N P}^{U P}<0$ in the unemployment expectations regression, the proportion of Coalition voters expecting a rise in unemployment over the next 12 months is about $\theta_{L N P}^{U P} \%$ lower during a Coalition government than a Labor government.

To investigate rigidities in updating expectations, Coibion and Gorodnichenko (2015a) examine the correlation between ex ante forecast revisions and ex post mean forecast errors. The relationship is positive (and one-for-one) if forecast errors are driven by agents only updating their forecast infrequently. Responses in CASiE are mostly ordinal and hence do not permit calculating forecast errors; no point forecasts for economic conditions and unemployment can be compared to actual realizations of economic conditions and unemployment. So, to investigate information rigidities in consumer expectations formation, 
we re-estimate equations (3) and (4) with lagged economic news:

$$
y_{i, t+12}^{j}=\alpha_{i}^{j}+\theta_{i}^{j} b_{i, t}+\boldsymbol{\beta}_{i}^{j \prime} \mathbf{x}_{t-p}+\epsilon_{i, t}^{j}, t=1, \ldots, T
$$

where $\mathbf{x}_{t-p}^{j}$, for $j=\{u, s d\}$, denotes economic news that are at least $p$ months old and everything else as before. This indicates how quickly news are incorporated into expectations and whether the rigidities vary across different types of news and across different expectations. This adds 16 additional regressions for each set of expectations.

Equation (5) also serves as a robustness check on the partisan bias. It may be possible that part of the emotional reaction immediately after the change of government is a reflection of expected changes in economic policy promised during the election campaign. If promised policy changes are enacted and do affect the economy, then $\theta_{i}^{j}$, for $j=\{u, s d\}$ and $i=\{$ Coalition, Labor $\}$, should lose statistical significance when lagged economic variables are included in the regression.

Limited dependent variable (LDV) models, such as probit models, are an alternative empirical framework. However, LDV models are not suitable for our dataset for two reasons. First, LDV models are for longitudinal panels. Our data is a repeated crosssection and the expectations of individual $i$ are not tracked over time. We are not able to investigate the change in individual $i$ 's expectations between periods $t$ and $t+1$ when there is a change in the government in period $t+1$. Second, our sample is relatively small (1200 consumers per month) as compared to usual longitudinal panels, so we have to use weights based on stratification factors (age, gender and location). We use weighted proportions of consumers instead of using individual data to yield valid inferences. Nevertheless, using proportions in our current specification yields similar interpretations to results from a probit model. Specifically, the proportions can be thought of as probabilities that party $i$ 's voters expect economic conditions, unemployment or inflation to go Up or Down/Remain unchanged. For example, the value of $\hat{\theta}_{A L P}^{u p}=-0.146$ for unemployment expectations can be interpreted as 'when the $A L P$ wins the election, ALP supporters lower the probability of an increase in the unemployment rate in the next 12 months by about $14.6 \%$ '.

\section{Estimation results}

Tables 3 to 6 give the results from applying equations (3) to (5) to the monthly dataset between February 1990 and May 2016. The tables present the parameter estimates and adjusted R-squared. The voting intentions dummies and all economic news (or their lags when estimating equation (5) ) were included in the estimation but only coefficients significant at the $5 \%$ level are presented in the tables. The tables are divided into two 
panels: Panel A presents the results for Labor voters and Panel B the results for Coalition voters. Each panel consists of two main sets of results: one for the Up proportion and the other for the Same/Down proportion. Columns 3 and 8 (latest news) provide the estimation results for equation (3) and equation (4) where all the latest available economic news are included $(p=0)$. The remaining columns show the results for estimating equation (5) in which the economic news are lagged 3, 6, 9 and 12 months $(p=3,6,9,12)$. The lagged results are used in Section 4.3 to examine information rigidities in consumer expectations.

Table 3 presents the results for unemployment expectations, Table 4 for expectations on economic conditions, and Tables 5 and 6 for inflation expectations based on ordinal and numerical responses. Statistical significance of $\theta$ suggests that emotional reactions affect consumer expectations while statistical significance of the remaining parameter estimates barring the constant, indicates coherent evaluations of economic news.

\subsection{Voting intentions}

Supporting the party in power leads to a more optimistic outlook. There is a remarkable consistency in the results for the effect of voting intentions on expectations formation across all specifications. Supporting the party that has formed government leads to more optimistic views on the labor market and the economy and a more subdued inflation outlook. Given that voting intentions are coded as dummy variables, not supporting the party in power leads to an overall more pessimistic outlook on unemployment and the economy and an intensifying inflation outlook.

\section{Unemployment expectations}

The results in Table 3 show that all estimates of $\theta$ are significantly different from zero at the $5 \%$ level. Fewer Labor voters expect a rise in unemployment over the next 12 months if Labor is in power and fewer Coalition voters expect a rise in unemployment under a Coalition government. Specifically, a Labor government decreases the proportion of Labor voters expecting a rise in unemployment over the next 12 months by about $14 \%$. A Coalition government decreases the proportion of Coalition voters that expect a rise in unemployment by around 15\%. A Labor government raises the proportion of Labor voter expecting unemployment to decline or stay the same by around $15 \%$ and a Coalition government raises the corresponding proportion of Coalition voters by around $13 \%$.

\footnotetext{
— Insert Table 3 around here ——
} 


\section{Outlook on economic conditions}

The estimated effects of voting intentions on expected economic conditions in Table 4 are consistent with those on unemployment expectations. Supporting the party in power raises the likelihood that a respondent expects improved economic conditions over the next 12 months. A Labor government raises the share of Labor voters expecting improved economic conditions by around $15 \%$ while a Coalition government raises the corresponding share of Coalition voters by about $18 \%$. Similarly, a Labor government decreases the proportion of Labor voters expecting the same or worse economic conditions by about $12 \%$ while a Coalition government decreases the proportion of Coalition voters expecting the same or worse economic conditions by about $20 \%$.

\section{— Insert Table 4 around here}

\section{Inflation expectations}

The results for inflation expectations formations are presented in Table 5 (based on ordinal responses) and in Table 6 (based on numerical responses). They show that, regardless of which inflation expectation measure is used, the effects of voting intentions on inflation expectations remain the same and consistent across Coalition and Labor voters. Importantly, the results give a particularly interesting insight into consumer expectations formations. If consumers consider higher inflation as 'bad' and lower inflation 'good', the estimated effects of voting intentions on inflation expectations are consistent with those on expected unemployment and economic conditions. But, from an economic theory perspective, the partisan bias results in inflation expectations formations that are inconsistent with expectations on unemployment and economic condition. Theoretically, higher (lower) economic growth and lower (higher) unemployment put upward (downward) pressure on inflation. Higher expected economic growth and lower expected unemployment should be associated with higher expected inflation, and lower expected economic growth and higher expected unemployment should be associated with lower expected inflation.

\section{— Insert Tables 5 and 6 around here -}

The results in Tables 5 and 6 show that supporting the party in power decreases the likelihood of a respondent expecting rising inflation pressures over the next 12 months (proxied by rising prices in Table 5 and by higher inflation in Table 6). A Labor government decreases the share of Labor voters expecting rising prices by about $3 \%$ (Table 5 ) and expecting higher inflation by about 6\% (Table 6). A Coalition government decreases the share of Coalition voters expecting rising prices by about $6 \%$ (Table 5) and expecting higher inflation by about $9 \%$ (Table 6). Similarly, a Labor government raises the share of 
Labor voters expecting subdued inflation pressures over the next 12 months (expecting the same or less inflation, Table 6) by around $5 \%$ and a Coalition government decreases the Coalition share by about $11 \%$ (Table 6). These results suggest that perceptions are important and may work against predictions from economic theory.

It is important to re-iterate that we cannot track respondents. Some voters may be disappointed by their preferred party and may switch to supporting a competitor. Some voters may switch to minor parties; Coalition voters typically switch to the far right One Nation and Labor voters to the far left Australian Greens party, and will no longer be part of our estimations. Some voters may switch from the Coalition to Labor and vice versa and will hence remain in our dataset. About 1 in 10 voters in Australia are swing voters, switching from one party to another between two successive elections. Leigh (2005) finds that foreign born voters are more likely to switch parties than the native born ${ }^{15}$ but they are as likely to switch from Coalition to Labor as they are to switch from Labor to Coalition which should limit the impact of swing voters on our results.

\subsection{Economic news}

The estimation results in Tables 3 to 6 also indicate the importance of economic news in consumer expectations formations. The effects of news on the expectations formation of both Coalition and Labor voters are similar in magnitude and direction and reveal some interesting results.

\section{Unemployment expectations}

For unemployment expectations, the important drivers are actual unemployment and target cash rate news and, to a lesser extend, news on real GDP. The effects of these drivers on Up and on Same/Down proportions are consistent with each other and similar in magnitude. The parameter estimates for the unemployment rate and real GDP growth have the expected sign. For both Labor and Coalition voters, a 1 percentage point rise in the unemployment rate increases the share of respondents expecting a rise in unemployment over the next 12 months by about $19 \%$ while a 1 percentage point rise in real GDP growth decreases that proportion by about $5 \%$.

Interestingly, consumers appear to take changes in the target cash rate as signals for the overall strength of the economy rather than considering the implications of a change in interest rates on unemployment (and overall economic conditions and inflation discussed

\footnotetext{
${ }^{15}$ About one quarter of the Australian population is foreign born; Australian Bureau of Statistics, http://www.abs.gov.au/ausstats/abs@.nsf/Lookup/by\%20Subject/1370.0 2010 Chapter Overseas\%20born\%20population\%20(3.6); Accessed 23 January 2018
} 
below). Here we do not attempt to identify monetary policy shocks and their effects on consumer expectations. Instead, we focus on how consumers interpret the signals from the change in the policy rate in relation to all other relevant economic information available to them. The results in Table 3 indicate that a 1 percentage point rise in the cash rate decreases the proportion of respondents expecting a rise in unemployment by $19 \%$. This suggests that a tightening in monetary conditions is associated with a more optimistic outlook on the labour market.

Target cash rate decisions are accompanied by Reserve Bank of Australia (RBA) media releases ${ }^{16}$ The releases accompanying tightening decisions typically point to higher inflationary pressures and economic expansion and the releases accompanying easings typically point to weaker growth outlook and moderating inflationary pressures. Various studies have shown that central banks outperform other market participants in economic forecasting (Mankiw et al. (2004); Coibion and Gorodnichenko (2015b)). Hubert (2015) shows that private forecasters also update their forecasts in response to central bank publications - curiously, the central bank's influence on private sector forecasts is not linked to central bank forecasting performance. Our results here suggest that statements on inflation and the economy affect consumer expectations, in line with Hubert (2015).

\section{Outlook on economic conditions}

The results for the effects of economic news on expected economic conditions over the next 12 months are consistent with those of unemployment expectations. Changes in unemployment, the cash rate, the stock market index and real GDP are important drivers and estimates have the opposite sign to those for unemployment expectations (i.e. consistent) and have smaller magnitudes. An increase in unemployment lowers the upward expectations on economic conditions. An increase in real GDP and in the stock market index raises the upward expectations. Monetary tightenings are associated with a more optimistic view of the economy while easings are associated with a more pessimistic outlook. The results suggest somewhat different magnitudes in parameter estimates for Labor compared to Coalition voters. Parameter estimates for the share of respondents expecting economic conditions over the next 12 months to stay the same or decrease are virtually the same as those for improved economic conditions just with opposite signs.

\section{Inflation expectations}

For both inflation expectations measures, based on ordinal responses in Table 5 and on numerical responses in Table 6, changes in the target cash rate and the latest inflation rate are important drivers while the effect of changes in share prices is muted. A 1 percentage

\footnotetext{
${ }^{16}$ The RBA has been announcing target cash rate changes since 1990. Prior to December 2007, media releases were issued only when the cash rate target was changed.
} 
point rise in the target cash rate raises the proportion of both Coalition and Labor voters expecting rising prices over the next 12 months by about $5 \%$ and raises the proportion expecting higher inflation over the next 12 month by about $9 \%$. Again, consumers appear to take changes in the target cash rate as signals for the overall strength of the economy rather than considering the implications of a change in interest rates on inflation. News about real GDP appears important for consumers' expectations on future price levels but appears less relevant for consumers' expectations on future inflation rates.

The effects of the current inflation rate are different for consumers' expectations on future price levels and expectations on the future inflation rate. Specifically, a 1 percentage point increase in the current inflation rate raises the proportion of Coalition and Labor voters expecting rising prices over the next 12 months by about 3\%, but it lowers the proportion of Coalition and Labor voters expecting higher inflation over the next 12 months by about $11 \%$. This difference likely results from the fact that Australia is an inflation-targeting country with a target band of $2-3 \%$ on average over the cycle. Hence, the latter result can be interpreted as an increase in the current inflation rate reducing the likelihood that the inflation rate will rise further over the next 12 months.

A point to note is that in general the magnitude of parameter estimates is considerably lower for inflation expectations than unemployment or the overall economic outlook. The regression fit (discussed below) for inflation expectations is also considerably lower than for the other sets of specifications. There are two potential explanations for this. One is that consumers have a less clear idea on what drives inflation than what drives unemployment and economic activity as suggested by Conover et al. (1986). An alternative explanation is that consumers have well anchored inflation expectations. Australia was an early adopter of inflation targeting (second in 1992 after New Zealand in 1990). If inflation expectations are firmly anchored within the RBA's 2-3\% target band, then economic news should have less effects on inflation expectations although Haller and Norpoth (1994) posit that inflation expectations of the general public "are not of the kind that anticipates government policies, unlike the expectations of bond traders." p. 648 . Nonetheless, the anchored inflation expectations seem a more likely explanation given that voting intentions also have a considerably smaller impact on inflation expectations than on unemployment expectations and the outlook on the overall economy.

\subsection{Information rigidities}

Tables 3 to 6 also explore information rigidities in expectations formation in columns 4 to 7 (Up proportion, news lagged by 3 to 12 months) and in columns 9 to 12 (Same/Down proportion, news lagged by 3 to 12 months). Mankiw et al. (2004) find that consumers 
incorporate new information into expectations every twelve months while Coibion and Gorodnichenko (2015b) find an average duration of six to seven months between information updates for consumers and private and public sector forecasters. Our results align with this literature. Economic news are incorporated into expectations by six months following the data release. There is a large decline in statistical significance of individual variables and the adjusted $\bar{R}^{2}$ when news are more than six months old. This seems to hold for the three sets of expectations, for Up and Same/Down proportions and for both Labor and Coalition voters.

Although the overall picture is similar, there are some differences. Unemployment, target cash rate and stock exchange news are incorporated into expectations relatively quickly, followed by changes in real GDP. For unemployment expectations, share market news are incorporated immediately and more quickly in Coalition voters' expectations than for Labor voters'. The importance of the stock market news may be due to the higher incidence of stock market investment among Coalition voters compared to Labor voters; see Chua and Claus (2011). Moreover, changes in the inflation rate are incorporated the most slowly in expectations on unemployment and economic conditions. Economic news appears to have less effect on inflation expectations than the other expectations, perhaps another sign of well anchored inflation expectations.

Interestingly, the magnitude of the parameter estimate of the voting intentions dummy remains quite constant at the different lag specifications. This supports the view that the political bias is a persistent bias and does not reflect parties coming good on election promises of economic policy changes. In contrast, rigidities in incorporating economic news into expectation formation generates a transient bias.

Coibion and Gorodnichenko (2015a) state that "[...] past information incorporated in other economic variables loses much of its predictive power for ex post mean forecast errors once we control for the forecast revisions. This indicates that the rejections of the null are unlikely to be driven by departures from rationality (such as adaptive expectations) and instead reflect deviations from the assumption of full-information." Coibion and Gorodnichenko, 2015a, p. 2646). The empirical results here suggest that irrationality cannot be so easily dismissed. If the partisan bias is persistent, there would be few forecast revisions and hence the correlation between forecast errors and forecast revisions would be low.

\subsection{Regression fit}

Tables 3 to 6 also present the adjusted $\bar{R}^{2}$ that gives an indication of regression fit. Overall, expectations on economic conditions display the best fit. About half of the 
variation in expectations on future economic conditions is explained by the changes in five key economic variables and the voting intentions dummy. The fit for unemployment expectations is slightly worse, under $50 \%$. The fit is different for the two measures of inflation expectations with inflation expectations based on numerical responses having slightly better fit. Nevertheless, the fit for inflation expectations is generally lower than that for expectations on unemployment and economic conditions. Maybe there is some merit to the argument that consumers have a clearer understanding of the unemployment process than the inflation process; see Conover et al. (1986).

\subsection{Testing for symmetries}

We test for two types of symmetry, symmetry within the results for Labor and for Coalition voters and for symmetry between the results for Labor and Coalition voters ${ }^{17}$ As a cross-check on people's responses, we investigate whether parameter estimates are of similar magnitude but opposite signs for respondents expecting a rise in unemployment, in economic conditions and in inflation compared to those respondents expecting no change or a decline in these three macroeconomic variables. We perform this cross-check within Labor voters and within Coalition voters. In addition, we check for symmetry between Labor and Coalition voters. Coalition voters typically differ from Labor voters. The poor, foreign born, younger voters, voters born since 1950, men, and those who are unmarried are more likely to vote Labor; see Leigh (2005). Voters who live in wealthier neighborhoods are more likely to vote Coalition while those in more ethnically diverse or unequal neighborhoods tend to vote Labor; see Leigh (2005). This raises the question whether household characteristics rather than voting intentions impact expectations. For example, if Coalition voters tend to be wealthier, it might be wealth that impacts expectations, in particular if one party favors or is perceived to favor social policy over economic policy.

Table 7 gives the test statistics from testing symmetry between the Up and the Same/ Down expectations. Table 8 reports those from testing symmetry between Labor and Coalition voters' expectations. Hypothesis testing is carried out in a 2-step procedure. In the first step, we regress the Up and Same/Down proportions on all the latest-news for Labor and Coalition voters. In the second step, we test two sets of symmetry hypotheses: (i) the estimated coefficients of the Same/Down proportions equal the corresponding coefficients of the Up proportions, for both Labor and Coalition voters; (ii) the estimated coefficients of Coalition voters equal the corresponding coefficients of Labor voters. For example, for testing within symmetry in unemployment expectations for Labor voters, the parameter estimate of the cash rate, $\beta_{r}$ in Table 3 Panel A, is -1.92 for the proportion

\footnotetext{
${ }^{17}$ We thank one of the anonymous referees for this point.
} 
of Labor voters expecting a rise in unemployment over the next 12 months and 1.93 for the proportion of Labor voters expecting no change or a decline in unemployment. The null hypothesis $\beta_{i}^{u}=-\beta_{i}^{s d}$ in this case translates into $H_{0}: \beta_{A L P}^{u}=-1.93$ and the Wald test statistic follows a Chi-squared distribution with one degree of freedom. For testing between symmetry in unemployment expectations for Labor and Coalition voters, the parameter estimate of the cash rate, $\beta_{r}$ in Table 3 Panel $\mathrm{A}$, is -1.92 for the proportion of Labor voters expecting a rise in unemployment over the next 12 months and -1.90 for the proportion of Coalition voters expecting a rise in unemployment over the next 12 months, $\beta_{r}$ in Table 3 Panel B. The null hypothesis $\beta_{A L P}^{u}=\beta_{L N P}^{u}$ in this case translates into $H_{0}: \beta_{A L P}^{u}=-1.90$ and the Wald test statistic follows a Chi-squared distribution with one degree of freedom. Rejection of the null hypothesis at a $5 \%$ significance level is indicated with bold numbers in Tables 7 and 8 . Overwhelmingly, the symmetry hypotheses are not rejected. The results for 3-month, 6-month and 12-month old news are qualitatively similar and are available from the authors.

If 'Don't know' was not a possible answer in the survey, the estimation results for Up and Same/Down proportions should be exactly opposite. Table 7 suggests that leaving out the 'Don't know' respondents does not affect the estimation results. The increase in Labor (Coalition) voters expecting a rise in the underlying macro series is of the same magnitude as the decrease in Labor (Coalition) voters expecting a decline in unemployment over the next 12 months with a Coalition (Labor) government. In addition, given within symmetry is not rejected at the $5 \%$ level, adding respondents who expect no change (the 'Same' proportion) to those expecting a decline (the 'Down' proportion) is sensible. In essence, Table 7 suggests that one set of estimations, either for the Up proportion or for the Same/Down proportion, is redundant. For the clarity of the argument, we chose to keep both sets of estimations.

Table 8 presents the results for testing the symmetry between responses of Labor and Coalition voters. Symmetry is not rejected for all but three sets of parameters. Between symmetry is rejected for the dummy on the proportion of respondents expecting economic conditions to remain the same or worsen over the next 12 months, and the effect of stock market news on unemployment expectations. The symmetry in the impact of macroeconomic news on expectations of both Labor and Coalition voters is perhaps surprising given the perceived differences in their socio-economic characteristics. For example, cash rate changes have similar impacts on expectations for both Labor and Coalition voters even though Coalition voters are perceived to be wealthier. This is in line with Leigh (2005) who finds that, controlling for incumbency, macroeconomic factors do not seem to affect partisan preferences in Australian elections between 1966 and 2001 leading Leigh (2005, p. 265) to conclude that "Australian voters apparently regard both major parties as equally capable of governing in booms and busts". 
However, rejecting between symmetry in the dummy variable for the proportion of respondents expecting no change or worsened economic conditions suggests that there are at least some difference in Coalition and Labor voters. A Labor government decreases the proportion of Labor voters expecting economic conditions to remain the same or decline over the next twelve months be about $12 \%(\theta=-0.128$ in Table 4 Panel A) while a Coalition government decreases that proportion of Coalition voters by about $20 \%(\theta=-0.207$ in Table 4 Panel B). This result may be driven by the higher proportion of older voters for the Coalition and more generous policies towards retirees by a Coalition than by a Labor government; see Leigh (2005). The rejection of between symmetry for share prices on unemployment expectations may reflect the higher incidence of stock market investment among Coalition than Labor voters.

\section{Robustness checks}

In our main analysis, we use economic news defined as 1-month changes in macroeconomic variables. Economic news can also be defined as quarterly or annual changes (i.e., adding information over $h$ months for $h=3,12$ ). To check the robustness of our main results, we re-estimate all regressions with economic news defined as quarterly and annual changes. The results for quarterly and annual changes are qualitatively and quantitatively similar to monthly changes. There is one small difference. The explanatory power is higher in regressions with quarterly and annual changes than in regressions with monthly changes. This is because monthly changes, by construction, are noisier than quarterly or annual changes. To investigate how quickly new economic information is incorporated into expectations as compared to election news, and without loss of generality, we present the results based on economic news defined as monthly changes in the paper 18

We conduct principal components (PC) analysis to verify that our chosen set of economic data is relatively representative and that the effects of the partisan bias on expectations are not due to the omission of key economic information. We consider 9 other publicly available major domestic and international economic data series. Additional domestic series include total credit growth, total monthly hours worked, retail trade, dwelling approvals and the AUD/USD exchange rate. Additional international series includes commodity prices, the US industrial production, the US S\&P 500 index, and the US Federal fund rate. Together with the 5 original data series, this creates a set of 14 major domestic and international economic data series. We then extract the first and the second principal components from this set to approximate news about the underlying state of the

\footnotetext{
${ }^{18}$ The results based on economic news defined as quarterly and annual changes are available on request.
} 
domestic economy and international conditions 19 Table 2 provides descriptive statistics for the changes in the additional economic data series and the two principal components. The ADF test suggests that all variables are stationary with the exception of total credit growth (for which the null of a unit root cannot be rejected at the $10 \%$ significance level). Figure 3 plots the changes in the additional economic data and the two principal components.

To investigate the effects of principal components on consumer expectations together with the partisan bias, we estimate the following model:

$$
y_{i, t+m}^{j}=\alpha_{i}^{j}+\theta_{i}^{j} b_{i, t}+\boldsymbol{\lambda}_{i}^{j \prime} \mathbf{f}_{t-p}+\epsilon_{i, t}^{j}, t=1, \ldots, T
$$

where $\mathbf{f}_{t}=\left(\mathrm{PC}_{1 t}, \mathrm{PC}_{2 t}\right)^{\prime}$ is a $2 \times 1$ vector of principal components, $j=\{\mathrm{Up}$, Same/Down $\}$, $\boldsymbol{\lambda}_{i}^{j}$ is a $2 \times 1$ vector of factor loadings. Similar to the empirical analysis in Section 4 , we consider $p=0,3,6,9,12$-month lagged news to investigate the effects of the principal components on consumer expectations over time; $p=0$ denotes the latest available information before each survey.

Insert Tables 9 and 10 around here

Table 9 provides the estimation results for Labor voters and Table 10 presents the estimation results for Coalition voters. Given the similar effects of news and partisan bias on both sets of inflation expectations measures, for simplicity we just provide the results for inflation expectations based on ordinal responses in this robustness exercise. First, the use of the principal components improves regression fit in most cases which reflects the richer information set. In line with the main results, the fit is greatest for expectations on economic conditions followed by unemployment expectations. Nevertheless, together with the voting intentions dummy, information from the principal components explains at most around $63 \%$ of the variation in expectations. Second, rises (falls) in the principal components are considered favorable (unfavorable) news (for both Labor and Coalition voters) since they lower (raise) consumers' unemployment expectations and raise (lower) consumers' expected inflation and economic condition. Next, significant factor loadings at longer lags of the principal components clearly indicate the presence of information rigidities though the degree of rigidities varies across different expectations. Finally, the effects of voting intentions on expectations remain, in directions and in magnitudes.

\footnotetext{
${ }^{19}$ In constructing the principal components, monthly observations of quarterly CPI inflation and real GDP growth are linearly interpolated from their quarterly values.
} 


\section{Implications for economists}

To sum up, coherent reasoning and emotions are both important for consumer expectations formations. Given our long time series and the performance of the Australian economy, our results are robust to business cycle fluctuations. The emotional partisan bias tends to be larger for upward expectations (Up) than for downward expectations (Same/Down) and seems larger for Coalition voters than Labor voters and the bias is largest for the overall economic outlook over the next twelve months followed by unemployment expectations. The partisan bias is smallest for inflation expectations, perhaps reflecting Australia's long history of inflation targeting. Nevertheless, the partisan bias is present and of similar magnitude for our two measures of inflation expectations. Interestingly, the actual inflation rate puts upward pressure on expected price rises but downward pressure on expected inflation, likely reflecting the RBA's well established track record of targeting inflation.

Consumers seem to form forecasts in terms of good and bad so that the partisan bias introduces inconsistencies for unemployment and inflation expectations from an economic theory point of view where high unemployment is associated with high inflation and low unemployment with low inflation. Lastly, consumers appear to take changes in the cash rate as signals for the outlook on the economy rather than incorporating interest rate adjustments into their expectations. Economic news have similar effects on expectations for both sets of voters. The biggest difference seems to be the greater importance Coalition voters put on share price compared to Labor supporters.

\section{Does the emotional partisan bias matter?}

Large and persistent emotional biases pose sizable challenges for macroeconomists. Emotional biases are not intuitive within an economics framework and are not easily incorporated into traditional theoretical macroeconomic models. And, perhaps disconcertingly, the partisan bias demonstrated here may not be the only emotional bias in consumer expectations formation 20 A key question is whether emotional biases matter. From a macroeconomic perspective, if about half of the population supports one side of the political spectrum and the other half of the populations supports the other side of the political spectrum, overly optimistic views of government supporters would be offset by overly pessimistic views by opposition supporters so that the partisan bias would wash out at the aggregate. However, the real economic implications of the partisan bias would only wash out if and only if voters are homogeneous in every other way except political persuasion. If the two groups have different marginal propensities to consume, to invest

\footnotetext{
${ }^{20}$ Claus and Nguyen $(2017)$ demonstrate that consumers are overoptimistic and overconfident and these cognitive biases affect their savings and borrowing decisions.
} 
or to save, there would be real political business cycle effects that are independent of the actual economic policies pursued by the different governments.

This may partly explain the higher real GDP growth outcomes in the U.S. when a Democratic President occupies the U.S. White House than when a Republican is President. Extending Comiskey and Marsh (2012), Blinder and Watson (2016) show that the U.S. economy has performed better under a Democratic than a Republican President where, "[o]n the spending side, much of the D[emocratic]-R[epublican] [GDP] growth gap comes from greater business spending on fixed investment and greater consumer spending on durables." (Blinder and Watson, 2016, p. 1043) It is surprising that the political affiliation of the President matters, who has comparatively little political power and not the majority in Congress (the executive) or the Senate (the legislative) or the majority in both houses. However, the partisan bias is typically with the President's party (Erikson $(2004)$; Gerber and Huber (2009)). If Republican consumers are distinct from Democratic consumers, this could lead to different economic growth outcomes for Republican compared to Democratic Presidents ceteris paribus. A natural test for this conjecture would be to apply the Blinder and Watson (2016) analysis to Australia. However, unlike the United States, a large and relatively closed economy, Australia is a small open economy whose business cycle is closely linked to foreign activity, particularly in the U.S. and China. So, signs of a political business cycle may not be easily recoverable in Australia.

\section{The Phillips curve}

Empirical results here have important implications for consumers' views of the Phillips curve. On the one hand, consumers form expectations that are consistent with the Phillips curve; see Tables 5 and 6. Rises in actual unemployment put downward pressure on inflation expectations. A 1 percentage point rise in the unemployment rate, leads to a $6-7 \%$ decline in the proportion of respondents expecting a rise in inflation in the next 12 months for both Labor and Coalition voters. A 1 percentage point rise in the unemployment rate, leads to an around $4 \%$ rise in Labor voters expecting stable or decelerating inflation and a $5-6 \%$ rise for Coalition voters.

Counteracting this economic theory view of the Phillips curve are the partisan bias effects. Viewed through political affiliation, high inflation and high unemployment is bad and low inflation and low unemployment is good so that respondents overall expect lower inflation and lower unemployment if the party they support is in power and expect higher inflation and higher unemployment if the party they support is in opposition. So, the partisan bias suggests an upward sloping Phillips curve where low inflation is associated with low unemployment and high inflation is associate with high unemployment. These two opposing influences on the relationship between unemployment and inflation expectations are consistent with Dräger et al. (2016) who test whether changes in consumer 
expectations in response to monetary policy news are consistent with economic theory. Using the Michigan survey, only about one third of US consumers have theory consistent expectations with respect to the Phillips curve.

\section{Monetary policy}

The Phillips curve is a key relationship monitored by central banks. Central bankers watch inflation expectations closely, because higher inflation expectations may feed into higher wages that feed into higher costs. Higher costs, in turn, put upward pressure on prices which may feed back into higher inflation expectations and higher wages, setting off a price-wage spiral. If inflation expectations do not evolve in line with the Phillips curve, this creates a potential for suboptimal monetary policy decisions.

The effects of the target cash rate changes on consumer expectations may also produce unwanted effects of monetary policy changes. If monetary policy tightenings are seen as signals of inflationary pressures that lead consumers to adjust upwards their outlook on inflation and growth, then the policy tightening realizes the opposite it aims to achieve. The same applies to a policy easing. A possible driver of this signaling interpretation of cash rate changes could be that consumers believe that the central bank has superior forecasting models and consumers are not convinced that the central bank will fully offset shocks. In that case the apparent consumer behavior would mean a lack of central bank credibility in achieving the inflation target.21 Another possible driver of the signaling interpretation of cash rate changes could be a household's net debt position (negative net assets). A policy tightening improves a household's financial position for respondents with positive net assets but deteriorates finances for a household with a net debt position. These personal experiences may influence the interpretation of cash rate changes. However, this does not seem to be the case here, as the interpretation of cash rate changes is robust to a household's financial position. Households in CASiE can be separated by home ownership: (i) rent; (ii) own home with a mortgage; and (iii) own outright. About $70 \%$ of household debt in Australia is housing debt $2{ }^{22}$ so home ownership is a reasonable proxy for a household's net debt position. Disaggregating expectations on unemployment, inflation and economic activity by home ownership status (renter, mortgager and outright owner) leads to similar results for expectations formations in response to cash rate changes. This suggests that the interpretation of cash rate changes is not dependent on a household's financial position 23

\footnotetext{
${ }^{21}$ Positive supply shocks are also consistent with rising output and falling inflation. Supply shocks would have to be frequent to affect our empirical results. Practically, economies generally experience demand shocks while supply are reasonably rare. Although rising commodity prices over the first half of the 2000s represented positive supply shocks for Australia, it does not seem sensible that supply shocks outweighed demand shocks over the estimation period.

${ }^{22}$ RBA Table E2 Household Finances - Selected Ratios

${ }^{23}$ Additional empirical results by home ownership status are provided on request.
} 


\section{Final thoughts}

Consumers are typically the largest group of agents in a developed market economy so understanding consumer behavior is paramount to developing reasonable models of the macroeconomy. Our results are in line with the information rigidities literature where consumers are asymptotically rational in response to economic news. Our contribution is that events that should, from an economic theory perspective, not affect consumer expectations persistently impact expectations. Consumptor economicus, the economic consumer, is more complex than homo economicus.

\section{References}

Barsky, R. B., Sims, E. R., 2012. Information, animal spirits, and the meaning of innovations in consumer confidence. American Economic Review 102 (4), 1343-1377.

Blanchard, O., 1997. Macroeconomics. Pearson Prentice Hall.

Blinder, A. S., Watson, M. W., 2016. Presidents and the US economy: An econometric exploration. American Economic Review 106 (4), 1015-1045.

Bovi, M., 2009. Economic versus psychological forecasting. Evidence from consumer confidence surveys. Journal of Economic Psychology 30 (4), 195-214.

Burden, B. C., Klofstad, C. A., 2005. Affect and cognition in party identification. Political Psychology 26 (6), 869-886.

Cao, M., Wei, J., 2005. Stock market returns: A note on temperature anomaly. Journal of Banking and Finance 29 (6), 269-298.

Carroll, C. D., 2003. Macroeconomic expectations of households and professional forecasters. The Quarterly Journal of Economics 118 (1), 269-298.

Carvalho, C., Nechio, F., 2014. Do people understand monetary policy? Journal of Monetary Economics 66 (September 2014), 108-123.

Chua, C. L., Claus, E., 2011. Consumer sentiment in Australia. In: Newton, P. (Ed.), Landscapes of Urban Consumption. CSIRO Publishing, Canberra, Australia, pp. 81-92.

Clarida, R., Gali, J., Gertler, M., 1999. The science of monetary policy: A new keynesian perspective. Journal of Economic Literature 37 (4).

Claus, E., Nguyen, V. H., 2015. Monetary policy shocks from the consumer perspective. mimeo.

Claus, E., Nguyen, V. H., 2017. The downside of being upbeat: Cognitive biases compel consumers to save less and borrow more. mimeo.

Coibion, O., Gorodnichenko, Y., 2015a. Information rigidities and the expectations formation process: A simple framework and new facts. American Economic Review 105 (8), $2644-2678$. 
Coibion, O., Gorodnichenko, Y., 2015b. Is the Phillips curve alive and well after all? Inflation expectations and the missing disinflation. American Economic Journal: Macroeconomics 7 (1), 197-232.

Comiskey, M., Marsh, L. C., 2012. Presidents, parties and the business cycle: 1949-2009. Presidential Studies Quarterly 42 (1), 40-59.

Conover, P. J., Feldman, S., Knight, K., 1986. Judging inflation and unemployment: The origins of retrospective evaluations. The Journal of Politics 48 (3), 565-588.

Conover, P. J., Feldman, S., Knight, K., 1987. The personal and political underpinnings of economic forecasts. American Journal of Political Science 48 (3), 559-583.

Dräger, L., Lamla, M. J., Pfajfar, D., 2016. Are survey expectations theory-consistent? The role of central bank communication and news. European Economic Review 85, $84-111$.

Edmans, A., García, D., Norli, Ø., 2007. Sports sentiment and stock returns. The Journal of Finance 62 (4), 1967-1998.

Erikson, R. S., 2004. Macro vs. micro-level perspectives on economic voting: Is the microlevel evidence endogenously induced? In: Prepared for the 2004 Political Methodology Meetings, July 29-31, 2004.

Evans, G., Andersen, R., 2006. The political conditioning of economic perceptions. The Journal of Politics 68 (1), 194-207.

Gali, J., Gertler, M., 1999. Inflation dynamics: A structural econometric analysis. Journal of Monetary Economics 44 (2), 195-222.

García-Schmidt, M., 2015. Monetary policy surprises and expectations. mimeo.

Gerber, A. S., Huber, G., 2009. Partisanship and economic behavior: Do partisan differences in economic forecasts predict real economic behavior? The American Political Science Review 103 (3), 407-426.

Greene, S., 2002. The social-psychological measurement of partisanship. Political Behavior 26 (3), 171-197.

Haller, H. B., Norpoth, H., 1994. Let the good times roll: The economic expectations of U.S. voters. American Journal of Political Science 38 (3), 625-650.

Hirshleifer, D., Shumway, T., 2003. Good day sunshine: Stock returns and the weather. The Journal of Finance 58 (3), 1009-1032.

Hubert, P., 2015. Do central bank forecasts influence private agents? Forecasting performance versus signals. Journal of Money, Credit and Banking 47 (4), 771-789.

Jackman, S., 2003. Political parties and electoral behavior. In: McAllister, I., Dowrick, S., Hassan, R. (Eds.), The Cambridge Handbook of Social Sciences in Australia. Cambrdige University Press, pp. 266-286.

Jasmand, S., Maenning, W., 2008. Regional income and employment effects of the 1972 Munich summer Olympic games. Regional Studies 42 (7), 991-1002. 
Kamstra, M. J., Kramer, L. A., Levi, M. D., 2003. Winter blues: A SAD stock market cycle. American Economic Review 93 (1), 324-343.

Lamla, M. J., Lein, S. M., 2014. The role of media for consumers' inflation expectations formation. Journal of Economic Behavior \& Organization 106, 62-77.

Leigh, A., 2005. Economic voting and electoral behavior: How do individual, local, and national factors affect the partisan choice? Economics \& Politics 17 (2), 265-296.

Lewis-Beck, M. S., 1988. Economics and the American voter: Past, present, future. Political Behavior 10 (1), 5-21.

Maenning, W., du Plessis, S., 2007. World cup 2010: South African economic perspectives and policy challenges informed by the experience of Germany 2006. Contemporary Economic Policy 25 (4), 578-590.

Malmendier, U., Nagel, S., 2016. Learning from inflation experiences. Quarterly Journal of Economics 131 (1), 53-87.

Mankiw, N. G., Reis, R., 2002. Sticky information versus sticky prices: A proposal to replace the New Keynesian Phillips curve. Quarterly Journal of Economics 117 (4), $1295-1328$.

Mankiw, N. G., Reis, R., Wolfers, J., July 2004. Disagreement about inflation expectations. NBER Macroeconomics Annual 78, 209-270.

Sims, C., 2003. Implications of rational inattention. Journal of Monetary Economics $50(3), 665-690$.

Singh, S. P., 2009. The dimensions of politics and voter behaviour in preferential systems: The case of Australia. Australian Journal of Political Science 44 (3), 421-437.

Suzuki, M., 1992. Political business cycles in the public mind. American Political Science Review 86 (4), 989-996.

Taylor, J., 1993. Discretion versus policy rules in practice. Carnegie-Rochester Conference Series on Public Policy 39, 195 - 214.

Wlezien, C., Franklin, M., Twiggs, D., 1997. Economic perceptions and vote choice: Disentangling the endogeneity. Political Behavior 19 (1), 7-17.

Woodford, M., 2003. Imperfect common knowledge and the effects of monetary policy. In: Aghion, P., Frydman, R., Stiglitz, J., Woodford, M. (Eds.), Knowledge, Information, and Expectations in Modern Macroeconomics. Princeton University Press, Princeton, pp. 25-58. 
Table 1: Descriptive Statistics for Consumer Expectations by Voting Intention

\begin{tabular}{lllllllll}
\hline & & & Mean & Stdev. & Min & Max & \multicolumn{2}{c}{ ADF test } \\
& & & & & & & t-stat & $p$-val \\
\hline Weighted & Labor & & 0.364 & 0.051 & 0.249 & 0.505 & & \\
Proportion & Coalition & & 0.321 & 0.053 & 0.205 & 0.515 & & \\
\hline Unemployment & Labor & UP & 0.408 & 0.180 & 0.092 & 0.901 & -2.938 & 0.042 \\
Expectations & Labor & S/D & 0.563 & 0.171 & 0.089 & 0.887 & -2.883 & 0.049 \\
(proportion) & Coalition & UP & 0.439 & 0.159 & 0.125 & 0.871 & -3.234 & 0.019 \\
& Coalition & S/D & 0.533 & 0.157 & 0.124 & 0.867 & -4.031 & 0.001 \\
\hline Economic & Labor & UP & 0.342 & 0.149 & 0.043 & 0.712 & -2.932 & 0.043 \\
Conditions & Labor & S/D & 0.598 & 0.164 & 0.253 & 0.912 & -3.331 & 0.014 \\
Expectations & Coalition & UP & 0.322 & 0.121 & 0.095 & 0.702 & -4.031 & 0.001 \\
(proportion) & Coalition & S/D & 0.614 & 0.121 & 0.243 & 0.898 & -4.088 & 0.001 \\
\hline Inflation & Labor & UP & 0.784 & 0.090 & 0.456 & 0.957 & -5.679 & 0.000 \\
Expectations I & Labor & S/D & 0.194 & 0.080 & 0.034 & 0.443 & -5.503 & 0.000 \\
(proportion) & Coalition & UP & 0.815 & 0.072 & 0.581 & 0.952 & -4.275 & 0.001 \\
& Coalition & S/D & 0.165 & 0.069 & 0.037 & 0.413 & -3.152 & 0.024 \\
\hline Inflation & Labor & UP & 0.478 & 0.133 & 0.075 & 0.795 & -5.143 & 0.000 \\
Expectations II & Labor & S/D & 0.405 & 0.130 & 0.121 & 0.852 & -5.057 & 0.000 \\
(proportion) & Coalition & UP & 0.500 & 0.136 & 0.120 & 0.766 & -3.623 & 0.006 \\
& Coalition & S/D & 0.382 & 0.131 & 0.101 & 0.741 & -4.285 & 0.001 \\
\hline
\end{tabular}

Note: 'Stdev.' denotes standard deviation. 'ADF' denotes Augmented Dickey-Fuller unit root test. The ADF test specification includes an intercept and the lag length is automatically selected based on Schwarz information criterion (SIC) with a maximum of 16 lags. 't-stat' denotes ADF test statistics and ' $p$-val' denotes the $p$-value. Up denotes up proportion and 'S/D' denotes same/down proportion. The proportions for Inflation Expectations I are computed based on ordinal responses to CIE question while the proportions for Inflation Expectations II are computed based on numerical responses to CIE follow-up question. These data are provided by the Melbourne Institute of Applied Economic and Social Research, the University of Melbourne. 
Table 2: Descriptive Statistics for Economic News

\begin{tabular}{lccccccc}
\hline $\begin{array}{l}\text { Change in } \\
\text { (\% or ppt.) }\end{array}$ & Mean & Stdev. & Min & Max & ADF test & Data \\
\hline Unemployment rate & 0.000 & 0.171 & -0.405 & 0.685 & -18.355 & 0.000 & ABS \\
Target cash rate & -0.052 & 0.277 & -1.750 & 1.000 & -8.122 & 0.000 & RBA \\
ASX/S\&P 200 index & 0.440 & 3.814 & -12.671 & 8.172 & -17.437 & 0.000 & ABS \\
GDP & 0.761 & 0.609 & -1.397 & 3.104 & -8.686 & 0.000 & ABS \\
CPI & 0.645 & 0.593 & -0.448 & 3.846 & -9.435 & 0.000 & ABS \\
\hline Credit & 0.664 & 0.422 & -0.536 & 1.814 & -2.547 & 0.105 & RBA \\
Hours worked & 0.104 & 0.623 & -2.403 & 2.134 & -23.576 & 0.000 & ABS \\
Retail trade & 0.419 & 1.129 & -10.605 & 8.058 & -19.473 & 0.000 & ABS \\
Dwelling approvals & 0.407 & 6.993 & -23.071 & 31.444 & -23.694 & 0.000 & ABS \\
AUD/USD & 0.054 & 3.199 & -16.458 & 8.906 & -16.117 & 0.000 & RBA \\
Commodity prices & 0.187 & 3.040 & -13.868 & 13.265 & -10.755 & 0.000 & RBA \\
US Ind. production & 0.154 & 0.638 & -4.303 & 2.047 & -4.754 & 0.000 & FRED \\
S\&P 500 index & 0.673 & 4.196 & -16.942 & 11.159 & -17.033 & 0.000 & FRED \\
US Federal fund rate & -0.025 & 0.177 & -0.960 & 0.530 & -6.297 & 0.000 & FRED \\
\hline Principal component 1 & 0.016 & 1.539 & -8.071 & 4.321 & -12.849 & 0.000 & \\
Principal component 2 & 0.008 & 1.464 & -6.285 & 3.895 & -4.343 & 0.000 & \\
\hline
\end{tabular}

NotE: The principal components ( 1 and 2 ) are constructed based the changes in all 14 economic data series. The frequency of all economic data, except for GDP and CPI (which are quarterly), is monthly. 'ABS' denotes the Australian Bureau of Statistics, 'RBA' denotes the Reserve Bank of Australia and 'FRED' denotes the Federal Reserve at St. Louis. 


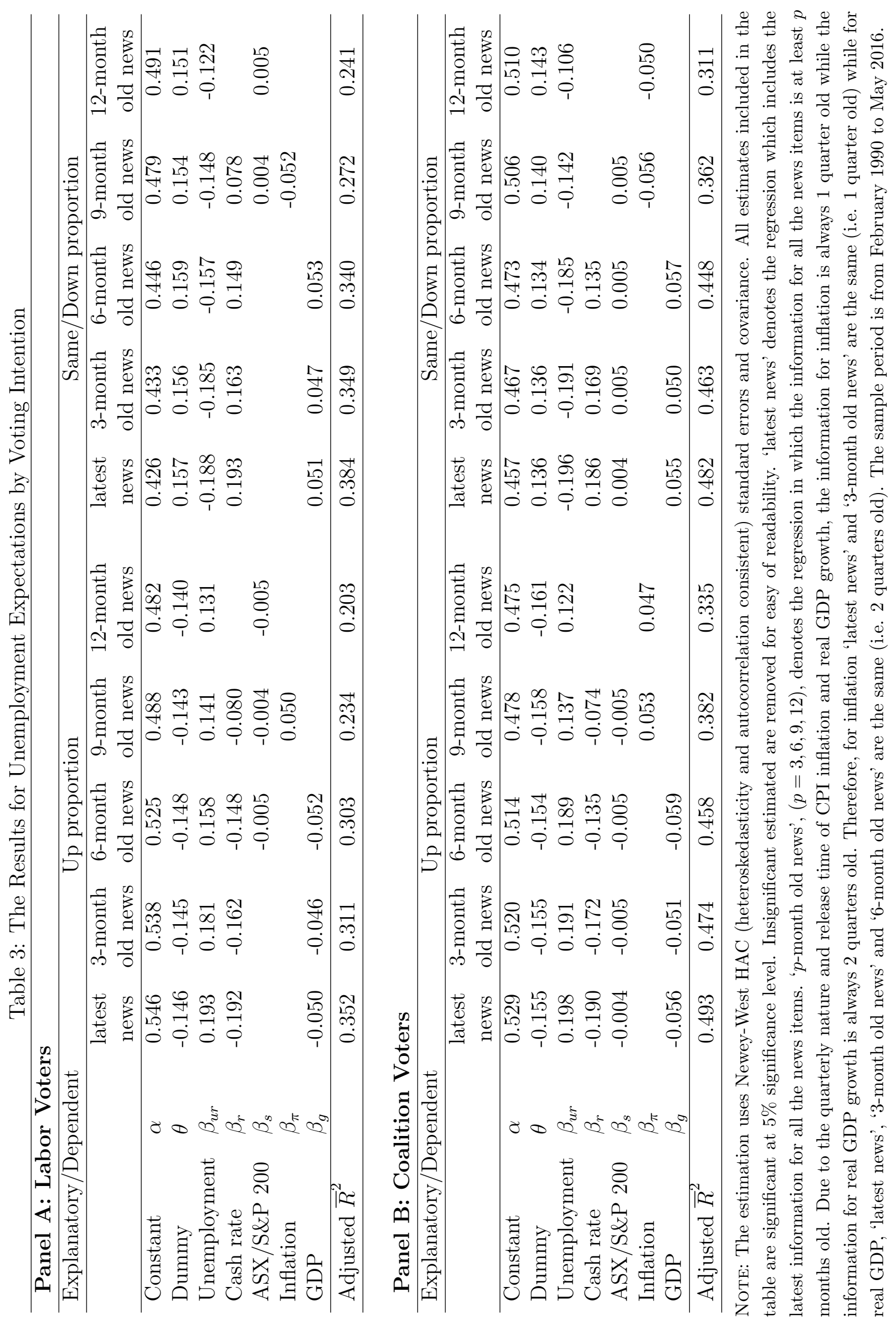




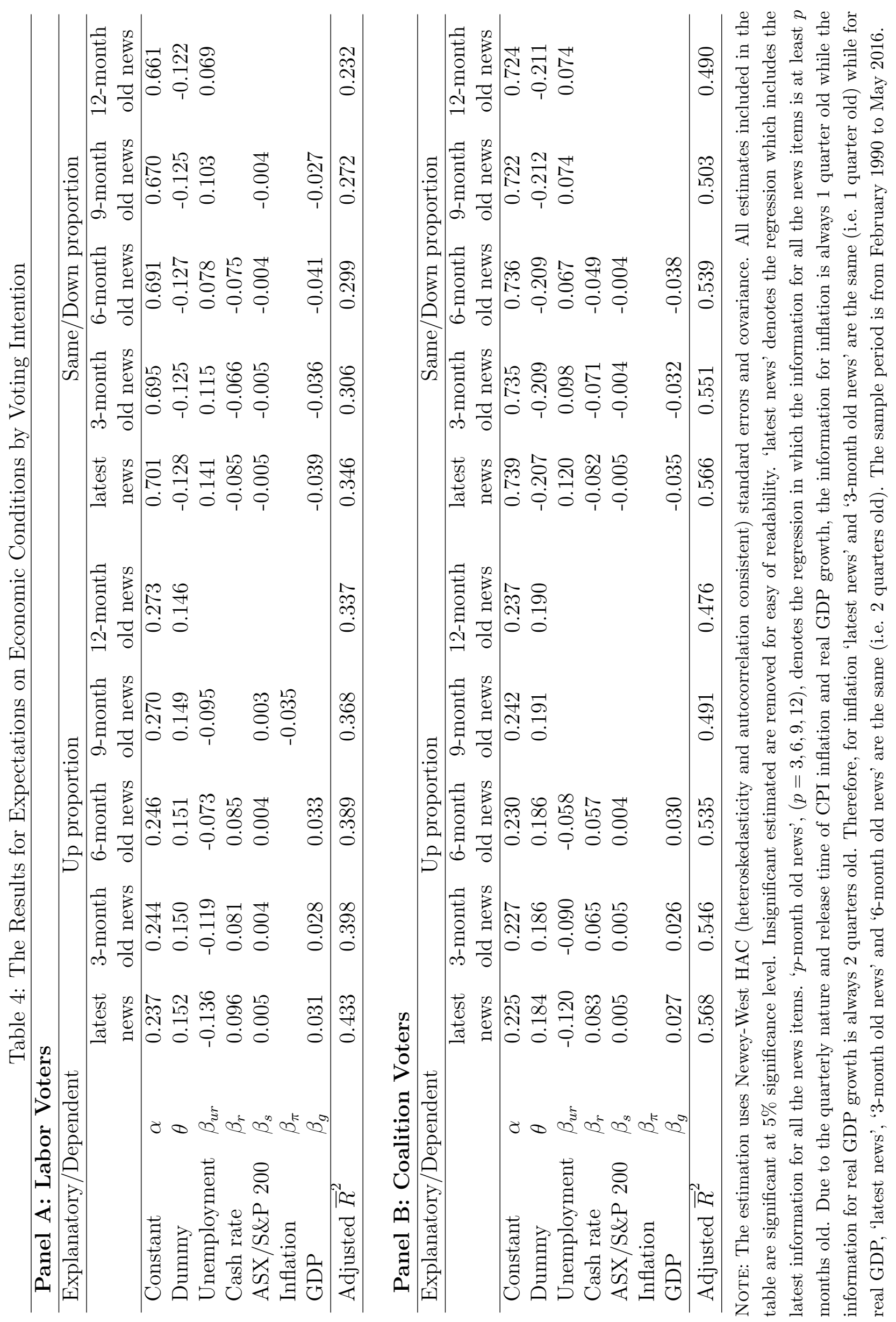




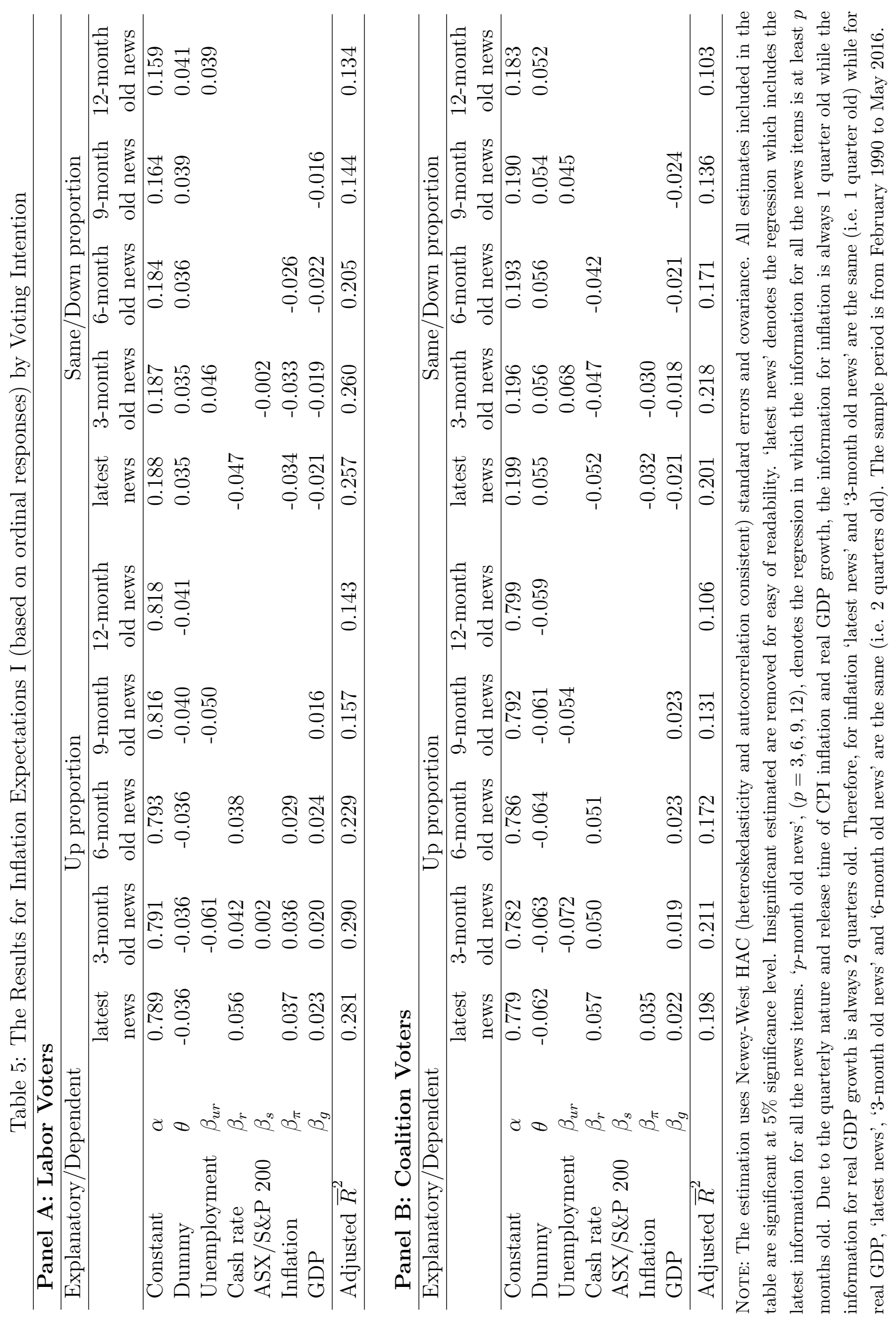




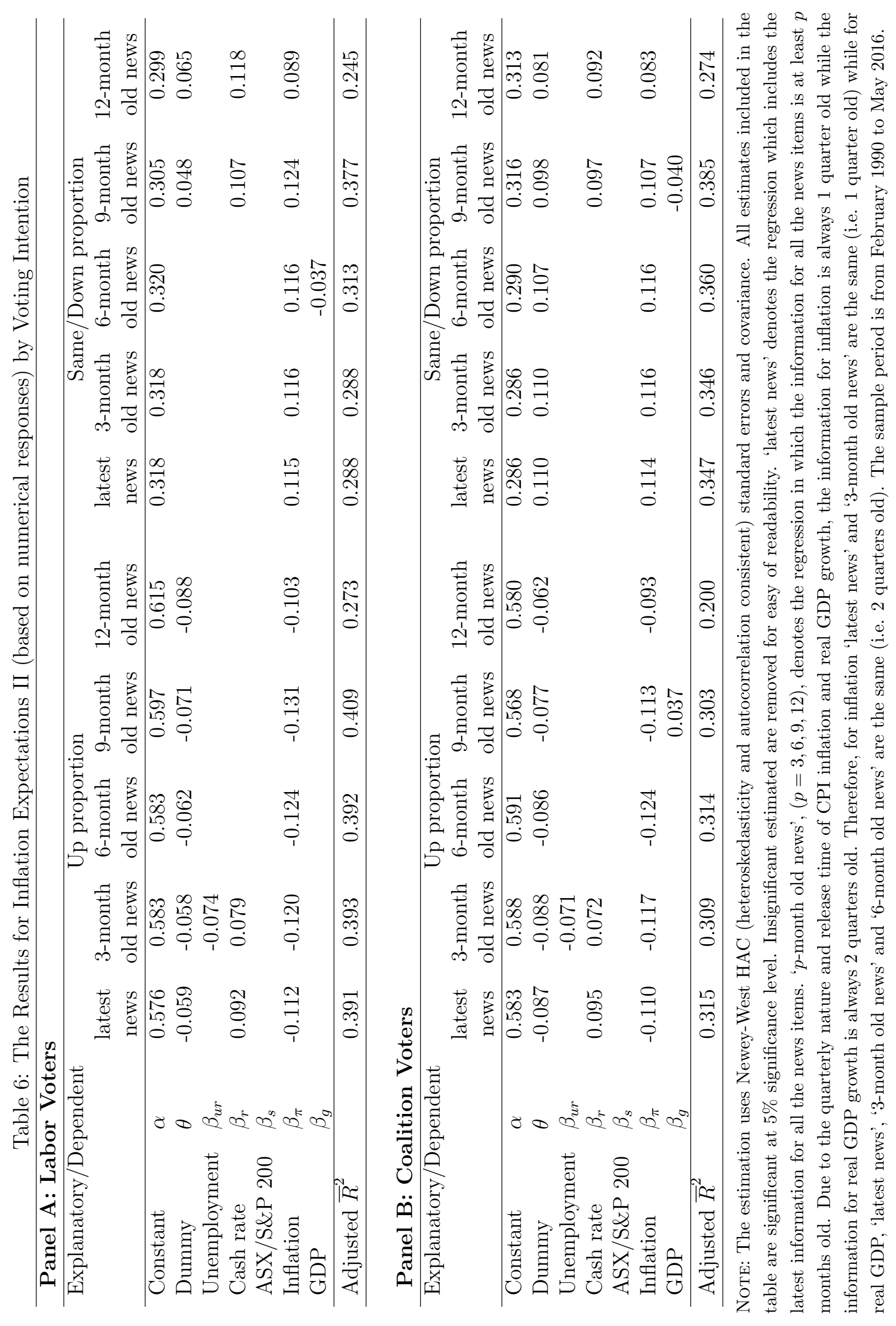


Table 7: Testing symmetry between Up and Same/Down Expectations

\begin{tabular}{lcccccc}
\hline & \multicolumn{3}{c}{ Labor Voters } & \multicolumn{3}{c}{ Coalition Voters } \\
& $C U E$ & $C E E$ & $C I E$ & $C U E$ & $C E E$ & $C I E$ \\
\hline Dummy & 0.160 & 1.226 & 0.002 & 0.437 & 0.858 & 0.201 \\
Unemployment & 0.009 & 0.014 & 2.552 & 0.002 & 0.000 & 3.185 \\
Cash rate & 0.002 & 0.649 & 0.291 & 0.030 & 0.002 & 0.122 \\
ASX/S\&P 200 & 3.166 & 0.001 & 2.370 & 0.004 & 0.071 & 0.025 \\
Inflation & 0.223 & 0.068 & 0.062 & 0.048 & 0.192 & 0.048 \\
GDP & 0.003 & 0.284 & 0.050 & 0.002 & 0.299 & 0.024 \\
\hline
\end{tabular}

Note: $C U E$ denotes Consumer Unemployment Expectations, CEE denotes Consumer Economic Conditions Expectations, and CIE denotes Consumer Inflation Expectations (based on ordinal responses). The table provides the Wald test statistics for testing the hypothesis of symmetry between Up and Same/Down Expectations, i.e $\theta_{i}^{u p}=-\theta_{i}^{\text {sd }}$ and $\beta_{i}^{u p}=-\beta_{i}^{\text {sd }}$ for $i=A L P, L N P$. All the Wald test statistics follow the Chi-squared distribution with one degree of freedom. Bold statistics indicate the rejection of the null hypothesis of symmetry at $5 \%$ significance level. The sample period is from February 1990 to May 2016.

Table 8: Testing Symmetry between Labor and Coalition Voters' Expectations

\begin{tabular}{lcccccc}
\hline & \multicolumn{3}{c}{ Up proportion } & \multicolumn{3}{c}{ Same/Down Proportion } \\
& $C U E$ & $C E E$ & $C I E$ & $C U E$ & $C E E$ & $C I E$ \\
\hline Dummy & 0.085 & 2.129 & 1.960 & 0.533 & $\mathbf{1 0 . 1 5 6}$ & 1.518 \\
Unemployment & 0.009 & 0.260 & 3.772 & 0.025 & 0.350 & 3.185 \\
Cash rate & 0.007 & 0.319 & 0.001 & 0.085 & 0.019 & 0.143 \\
ASX/S\&P 200 & $\mathbf{6 . 7 5 0}$ & 0.066 & 0.025 & $\mathbf{6 . 7 2 9}$ & 0.071 & 0.025 \\
Inflation & 0.017 & 0.028 & 0.022 & 0.048 & 0.192 & 0.024 \\
GDP & 0.127 & 0.088 & 0.008 & 0.070 & 0.082 & 0.002 \\
\hline
\end{tabular}

Note: $C U E$ denotes Consumer Unemployment Expectations, CEE denotes Consumer Economic Conditions Expectations, and CIE denotes Consumer Inflation Expectations (based on ordinal responses). The table provides the Wald test statistics for testing the hypothesis of symmetry between Expectations of Labour Voters and Expectations of Coalition Voters, i.e $\theta_{A L P}^{j}=\theta_{L N P}^{j}$ and $\beta_{A L P}^{j}=\beta_{L N P}^{j}$ for $j=U p$, Same/Down. All the Wald test statistics follow the Chi-squared distribution with one degree of freedom. Bold statistics indicate the rejection of the null hypothesis of symmetry at $5 \%$ significance level. The sample period is from February 1990 to May 2016. 


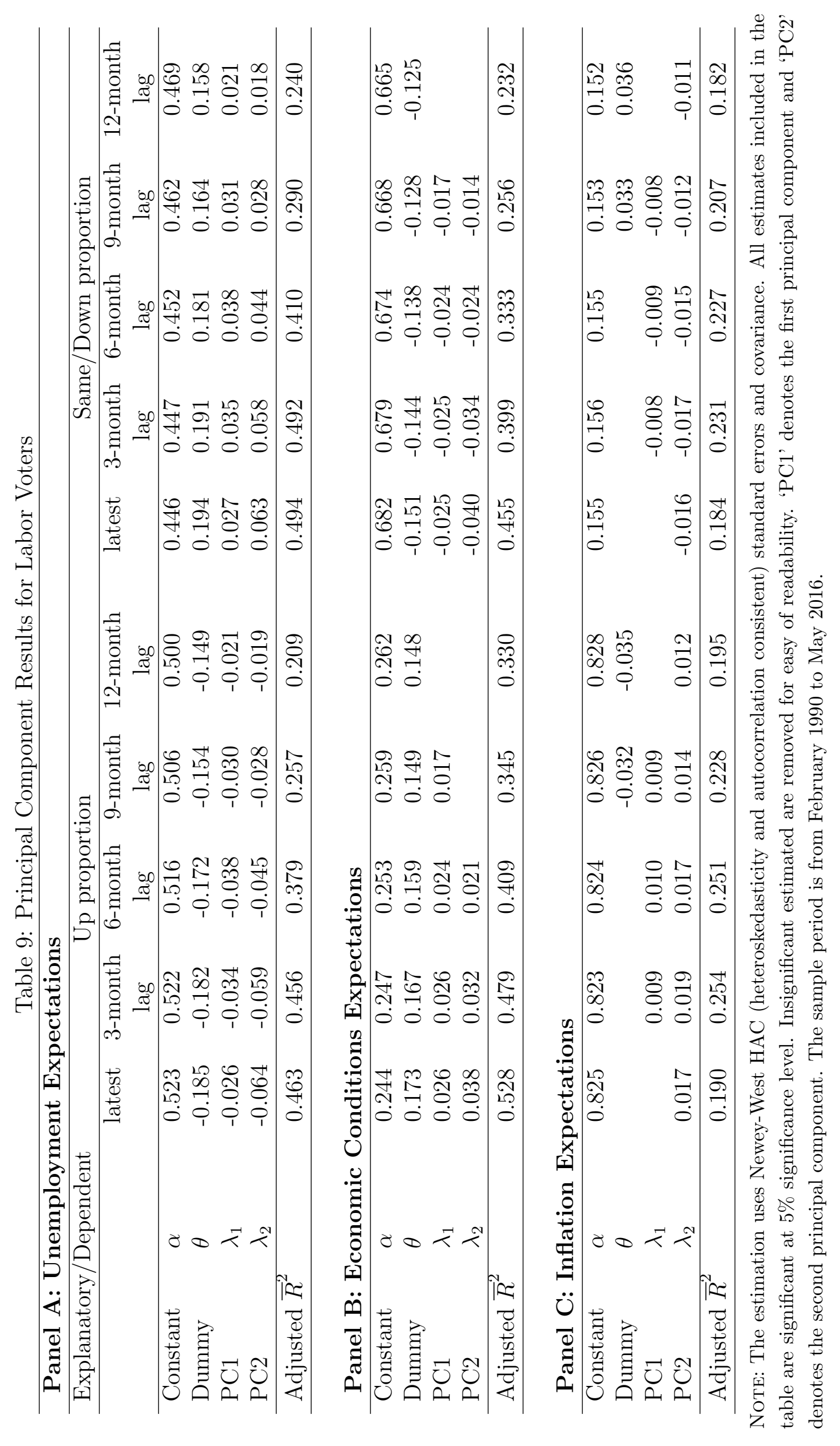




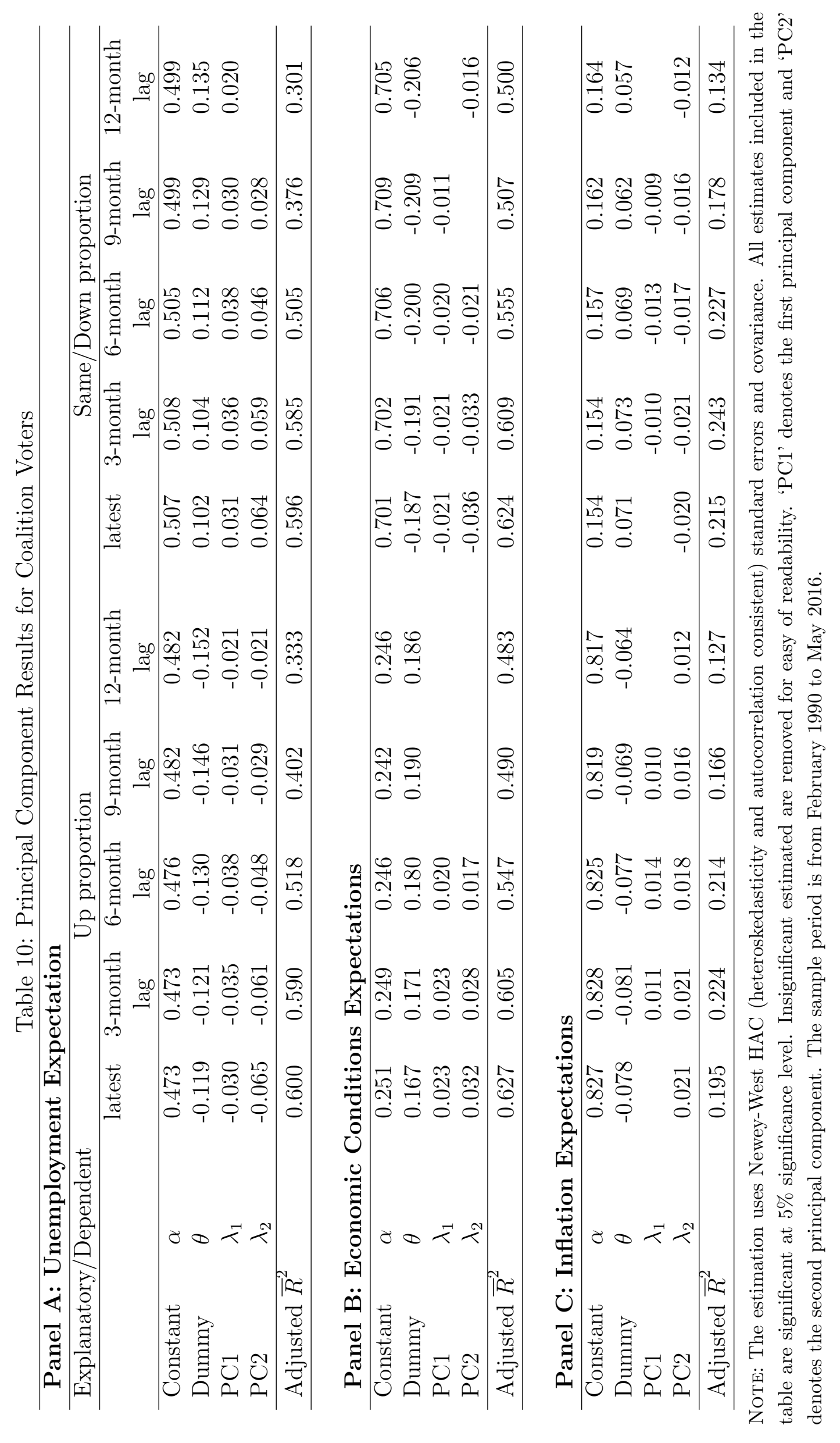


Figure 1: Expectations Data of Labor and Coalition Voters

(a) Proportions of Labor Voters (\%)

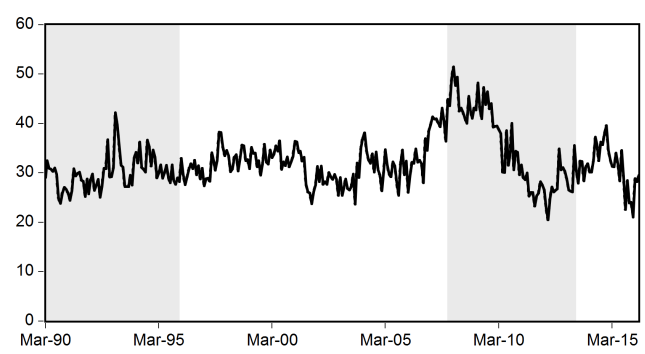

(c) Unemployment Expectations: UP proportions (\%)

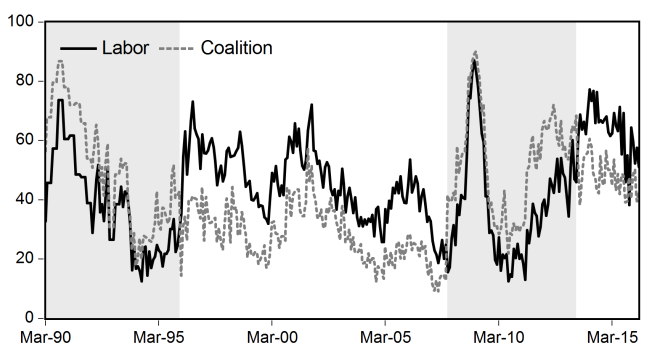

(e) Economic-Conditions Expectations: UP proportions (\%)

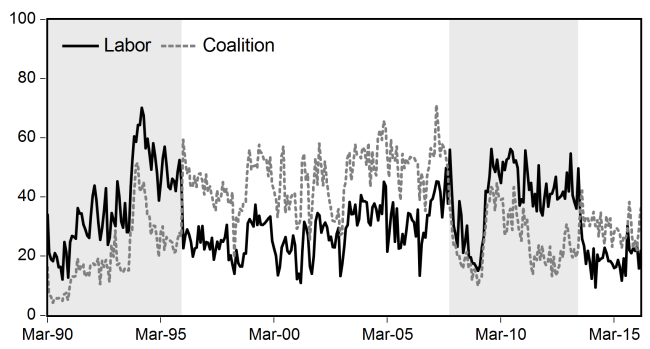

(g) Inflation Expectations I: UP proportions (\%, qualitative)

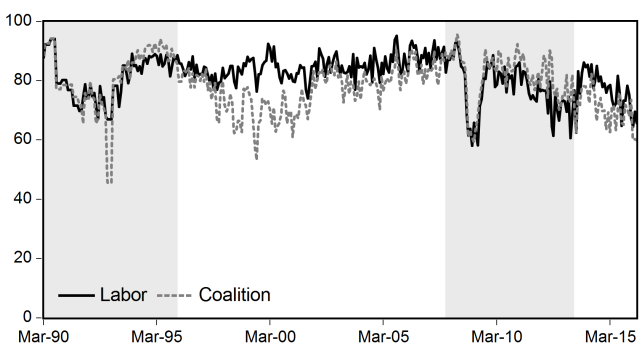

(i) Inflation Expectations II: UP proportions (\%, quantitative)

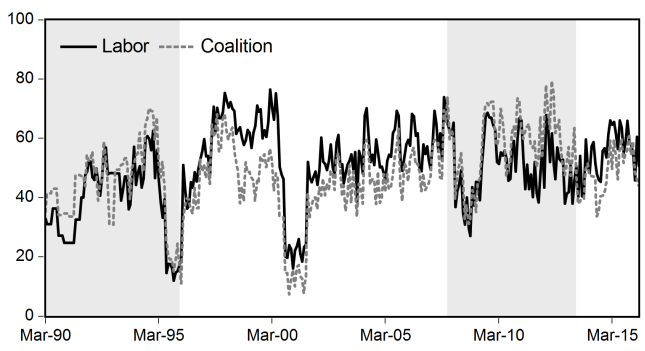

(b) Proportions of Coalition Voters (\%)

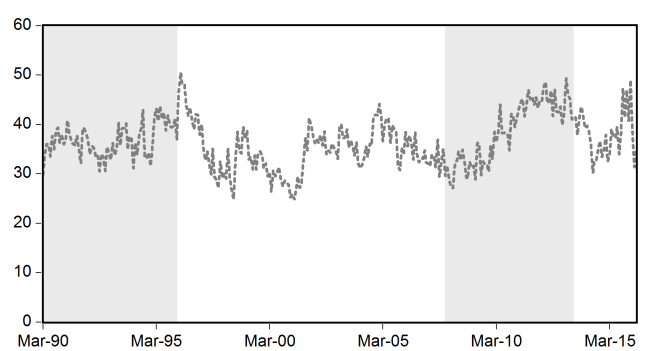

(d) Unemployment Expectations: SAME/DOWN proportions (\%)

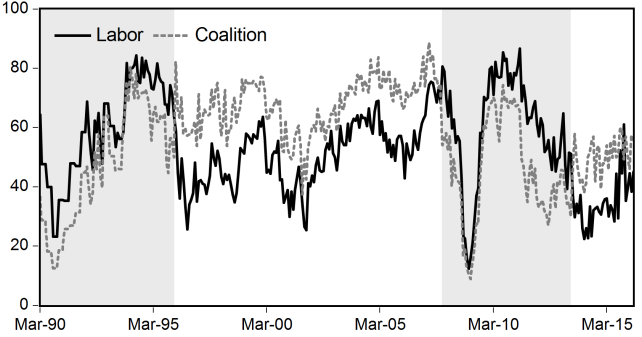

(f) Economic-Conditions Expectations: SAME/DOWN proportions (\%)

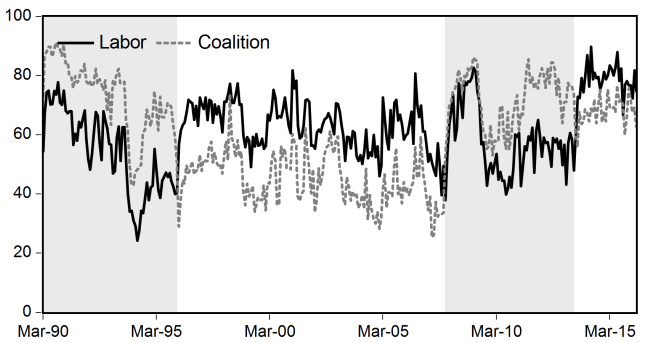

(h) Inflation Expectations I: SAME/DOWN proportions (\%, qualitative)

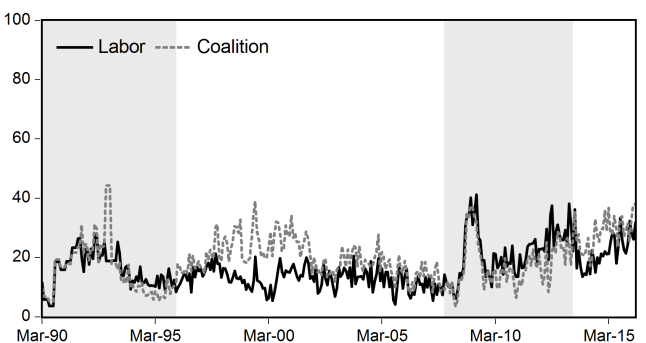

(j) Inflation Expectations II: SAME/DOWN proportions (\%, quantitative)

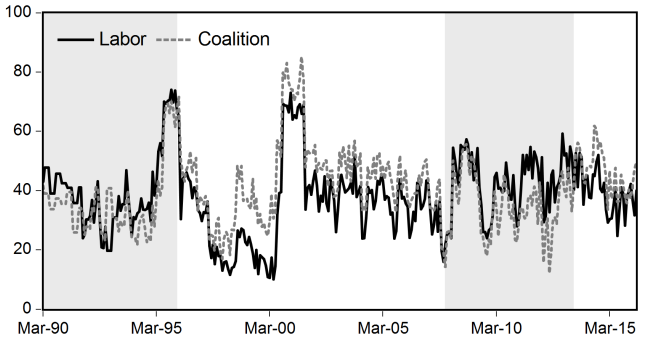

Note: Shaded (unshaded) areas indicate periods when Labor (Coalition) is in office. 

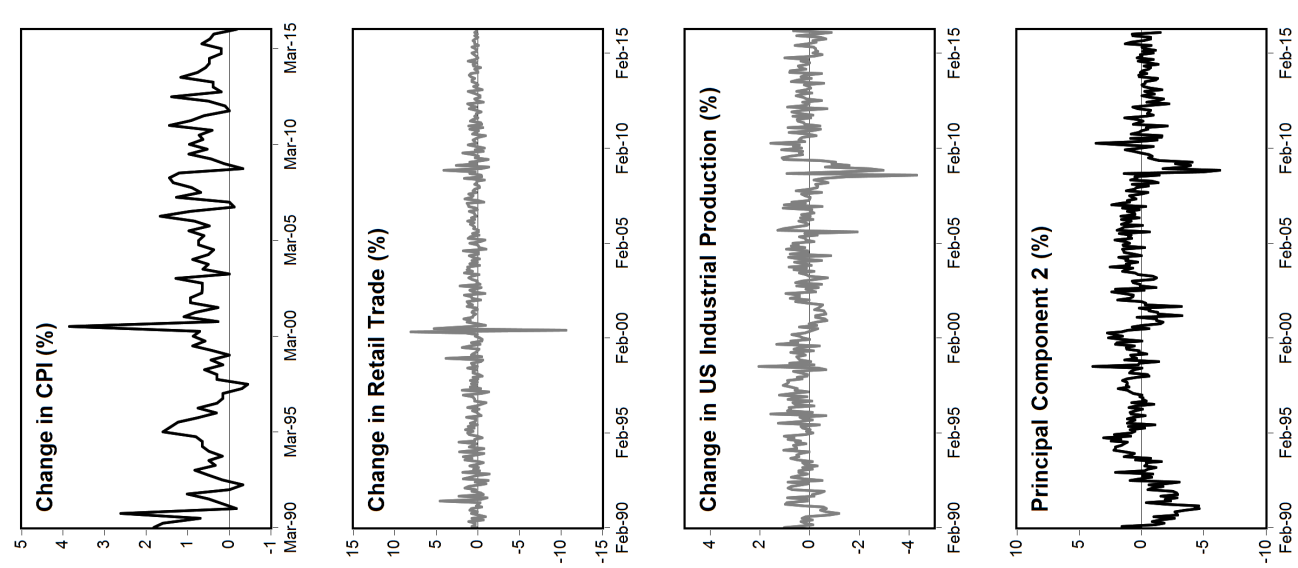

붕

들 윰

离

莡

号泀

:

苟

है
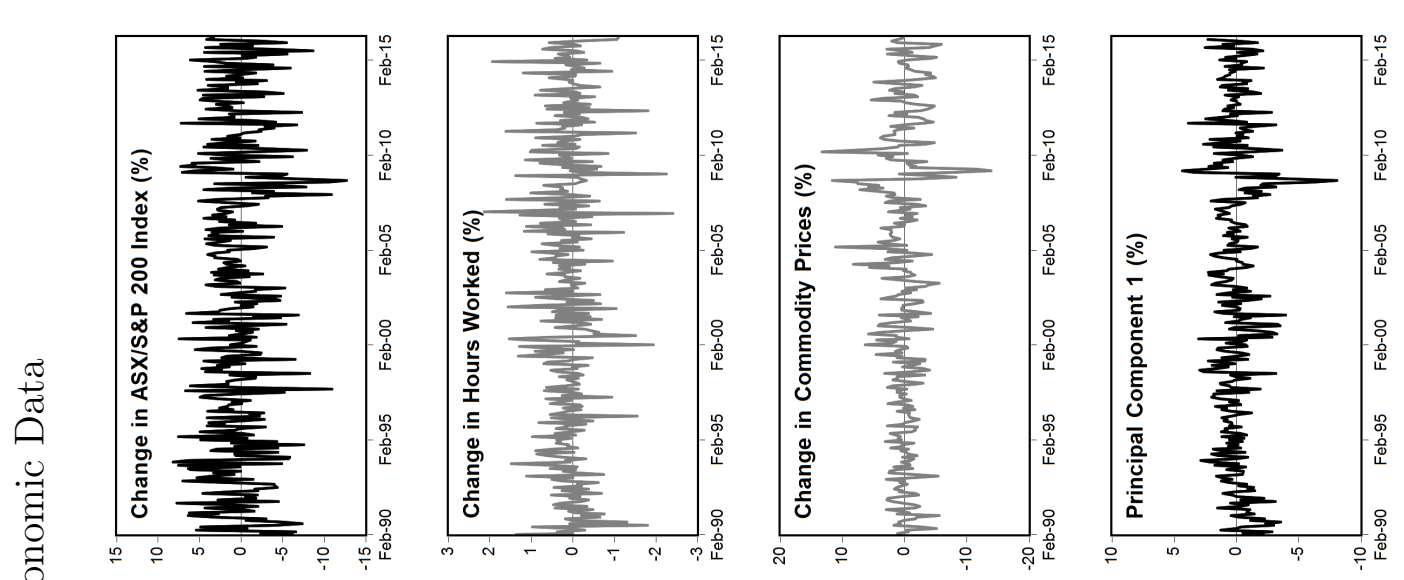

융

武
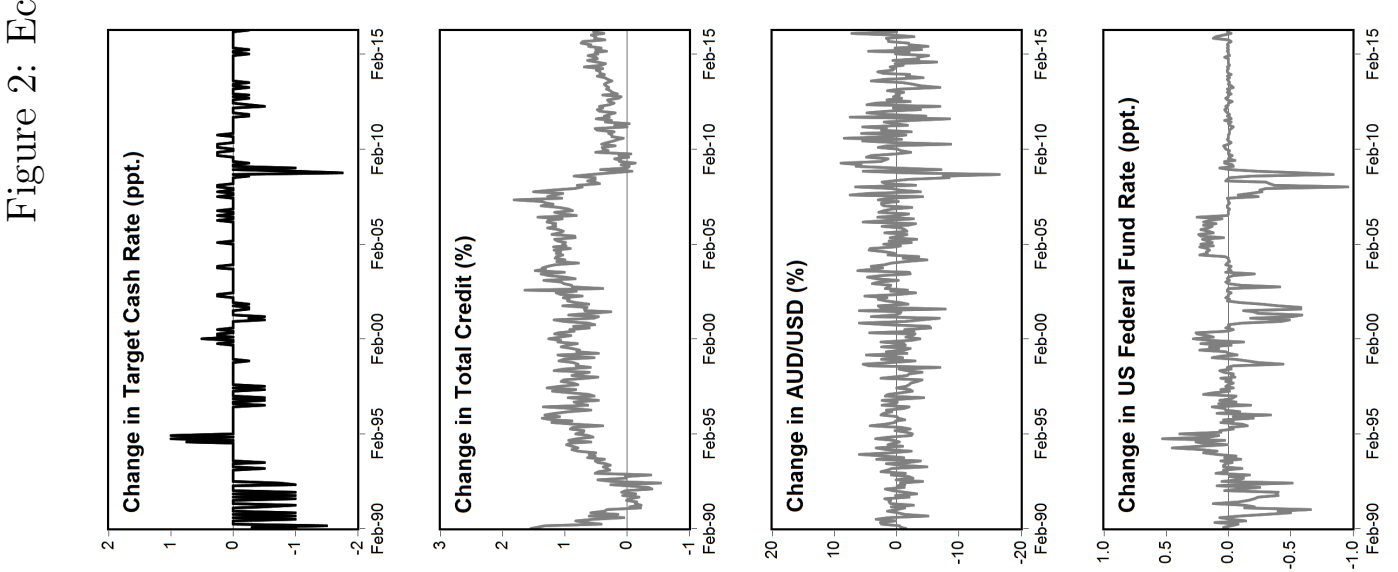

$\exists$ శี

ర్ల
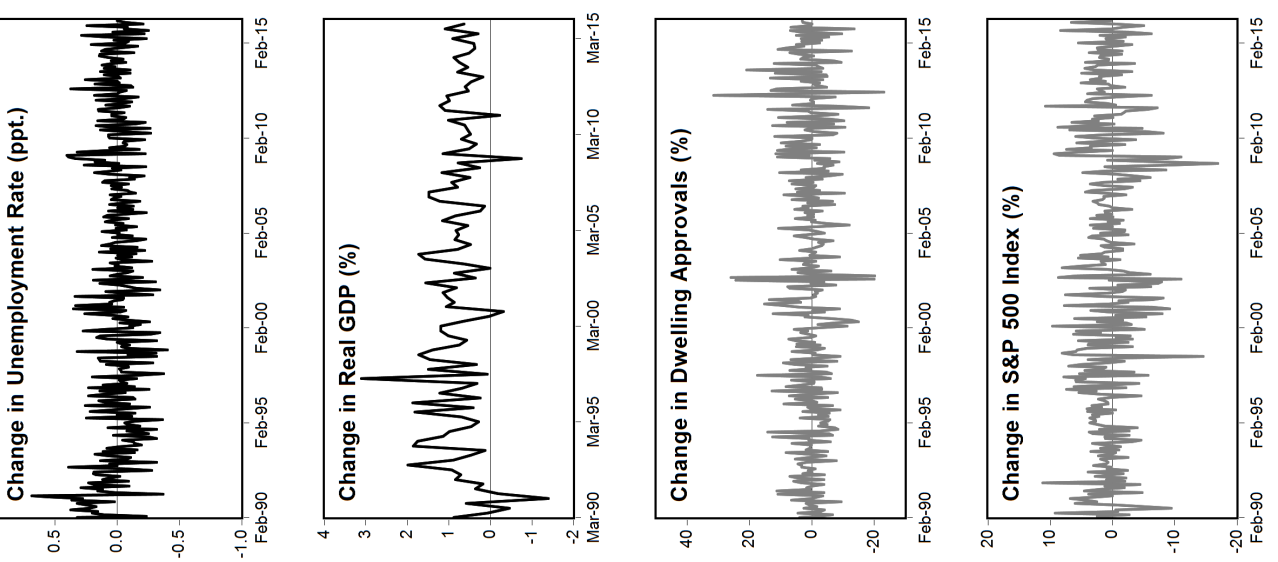

๑) 它

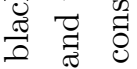

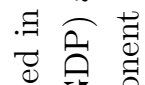
苍 Ш 串 क \&.

뭉 节 0 80 范

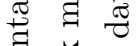
总 㐘

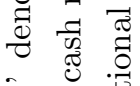

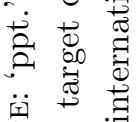

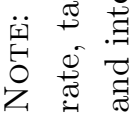


Figure 3: Responses to E5Y Innovation

Responses to E5Y Inovation (ordered first)
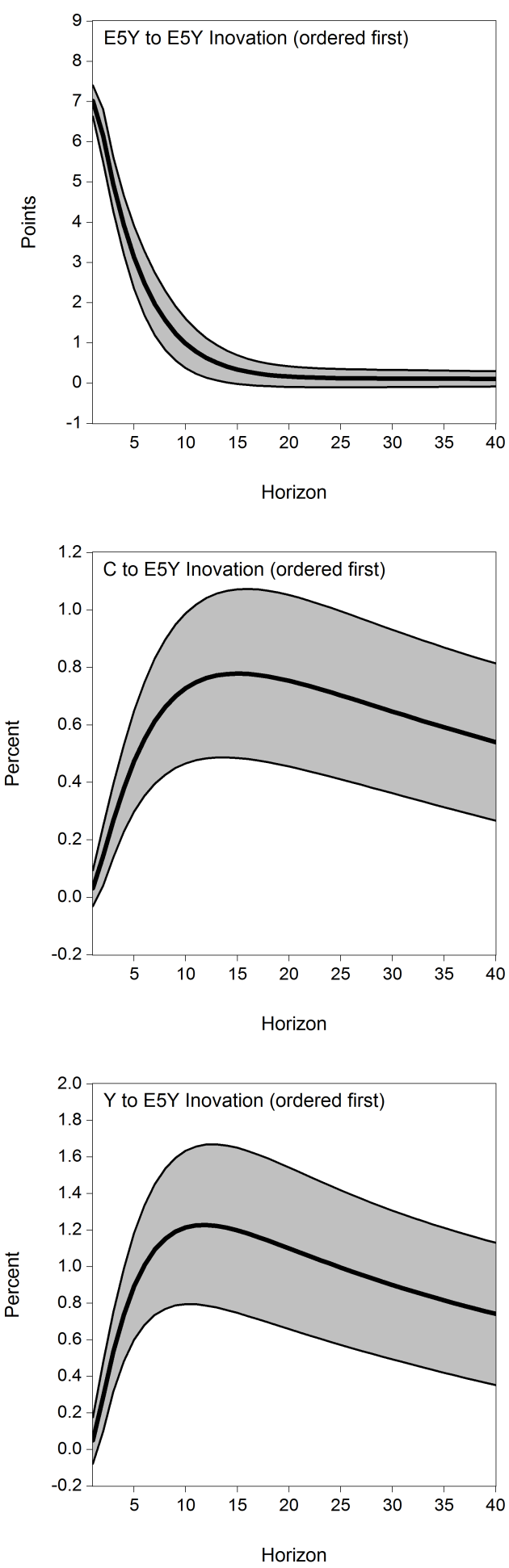

Responses to E5Y Inovation (ordered last)
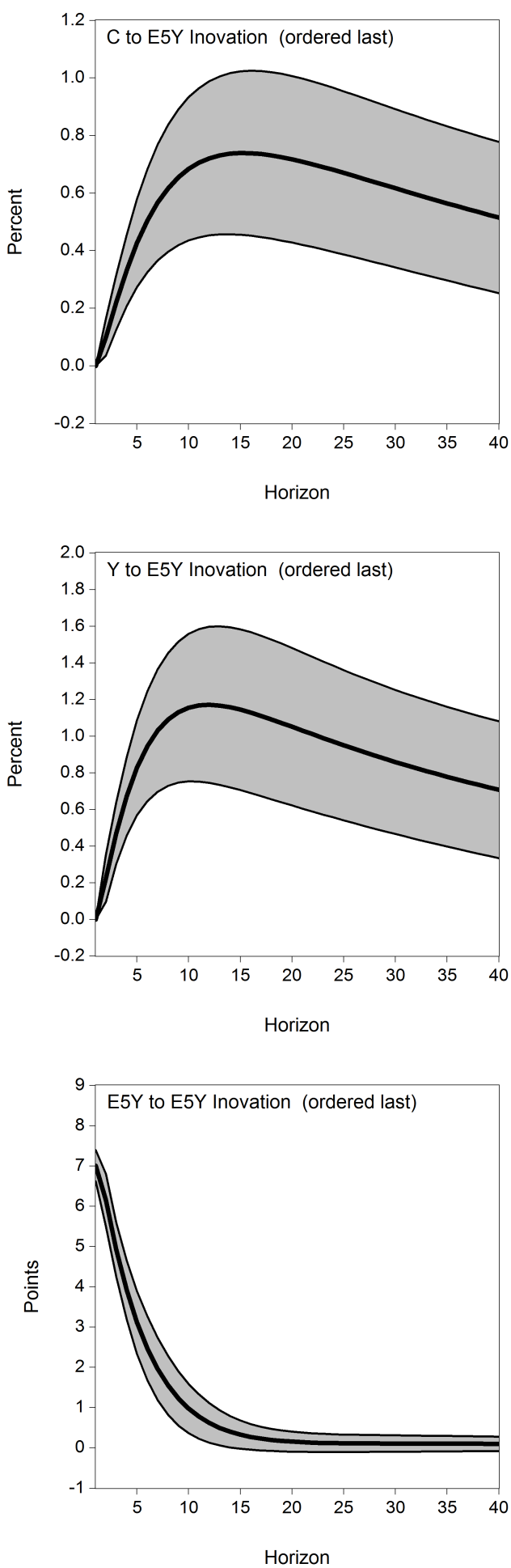

Note: 'E5Y' denotes the Index for Consumer Expectations of Economic Conditions in the next 5 years; ' $\mathrm{C}$ ' denotes detrended real household consumption (Australian Bureau of Statistics cat.no.5206.002); and 'Y' denotes detrended real GDP (Australian Bureau of Statistics cat.no.5206.002). 